\title{
Chemistry, Biosynthesis, Physicochemical and Biological Properties of Rubiadin: A Promising Natural Anthraquinone for New Drug Discovery and Development
}

Mohd Nasarudin Watroly, iD

Mahendran Sekar, (ID)' Shivkanya Fuloria, ${ }^{2}$ Siew Hua Gan, (ID ${ }^{3}$ Srikanth Jeyabalan, (ID) ${ }^{4}$ Yuan Seng $\mathrm{Wu},{ }^{5,6}$

Vetriselvan Subramaniyan, ${ }^{7}$

Kathiresan V Sathasivam, ${ }^{8}$ Subban Ravi, ${ }^{9}$

Nur Najihah Izzati Mat Rani, ${ }^{10}$

Pei Teng Lum,' Jaishree Vaijanathappa,"

Dhanalekshmi Unnikrishnan Meenakshi, ${ }^{12}$

Shankar Mani, ${ }^{13}$ Neeraj Kumar Fuloria ${ }^{2}$

'Department of Pharmaceutical Chemistry, Faculty of Pharmacy and Health Sciences, Universiti Kuala Lumpur Royal College of Medicine Perak, Ipoh, Perak, 30450, Malaysia; ${ }^{2}$ Faculty of Pharmacy \& Centre of Excellence for Biomaterials Engineering, AIMST University, Kedah, 08100, Malaysia; ${ }^{3}$ School of

Pharmacy, Monash University Malaysia, Bandar Sunway, Selangor Darul Ehsan, 47500 , Malaysia; ${ }^{4}$ Department of Pharmacology, Sri Ramachandra Faculty of Pharmacy, Sri Ramachandra Institute of Higher Education and Research (DU), Chennai, Tamil Nadu, 600I I6, India ${ }^{5}$ Centre for Virus and Vaccine Research, School of Medical and Life Sciences, Sunway University, Selangor, 47500, Malaysia; ' ${ }^{\circ}$ epartment of Biological Sciences, School of Medical and Life Sciences, Sunway University Selangor, 47500, Malaysia; ${ }^{7}$ Faculty of Medicine, Bioscience and Nursing, MAHSA University, Selangor, 42610, Malaysia; ${ }^{8}$ Faculty of Applied Science \& Centre of Excellence for Biomaterials Engineering, AIMST University, Kedah, 08100 , Malaysia; ${ }^{9}$ Department of Chemistry, Karpagam Academy of Higher Education, Coimbatore, Tamil Nadu, 640 02I, India; ${ }^{10} \mathrm{Faculty}$ of Pharmacy and Health Sciences, Universiti Kuala Lumpur Royal College of Medicine Perak, Ipoh, Perak, 30450, Malaysia; "Department of Pharmaceutical Chemistry, School of Life Sciences, JSS Academy of Higher Education and Research Mauritius, Vacoas, Mauritius; ${ }^{12}$ College of Pharmacy, National University of Science and Technology, Muscat, I30, Oman;

${ }^{13}$ Department of Pharmaceutical Chemistry, Sri Adichunchanagiri College of Pharmacy, Adichunchanagiri University, Mandya, Karnataka, 57|418, India

Correspondence: Neeraj Kumar Fuloria; Shivkanya Fuloria

Faculty of Pharmacy \& Centre of Excellence for Biomaterials Engineering, AIMST University, Kedah, 08100, Malaysia

Tel +60 I6 4037685; +60 I4 3034057

Email neerajkumar@aimst.edu.my;

shivkanya_fuloria@aimst.edu.my
Abstract: Anthraquinones (AQs) are found in a variety of consumer products, including foods, nutritional supplements, drugs, and traditional medicines, and have a wide range of pharmacological actions. Rubiadin, a 1,3-dihydroxy-2-methyl anthraquinone, primarily originates from Rubia cordifolia Linn (Rubiaceae). It was first discovered in 1981 and has been reported for many biological activities. However, no review has been reported so far to create awareness about this molecule and its role in future drug discovery. Therefore, the present review aimed to provide comprehensive evidence of Rubiadin's phytochemistry, biosynthesis, physicochemical properties, biological properties and therapeutic potential. Relevant literature was gathered from numerous scientific databases including PubMed, ScienceDirect, Scopus and Google Scholar between 1981 and up-to-date. The distribution of Rubiadin in numerous medicinal plants, as well as its method of isolation, synthesis, characterisation, physiochemical properties and possible biosynthesis pathways, was extensively covered in this review. Following a rigorous screening and tabulating, a thorough description of Rubiadin's biological properties was gathered, which were based on scientific evidences. Rubiadin fits all five of Lipinski's rule for drug-likeness properties. Then, the in depth physiochemical characteristics of Rubiadin were investigated. The simple technique for Rubiadin's isolation from $R$. cordifolia and the procedure of synthesis was described. Rubiadin is also biosynthesized via the polyketide and chorismate/o-succinylbenzoic acid pathways. Rubiadin is a powerful molecule with anticancer, antiosteoporotic, hepatoprotective, neuroprotective, anti-inflammatory, antidiabetic, antioxidant, antibacterial, antimalarial, antifungal, and antiviral properties. The mechanism of action for the majority of the pharmacological actions reported, however, is unknown. In addition to this review, an in silico molecular docking study was performed against proteins with PDB IDs: 3AOX, 6OLX, 6OSP, and 6SDC to support the anticancer properties of Rubiadin. The toxicity profile, pharmacokinetics and possible structural modifications were also described. Rubiadin was also proven to have the highest binding affinity to the targeted proteins in an in silico study; thus, we believe it may be a potential anticancer molecule. In order to present Rubiadin as a novel candidate for future therapeutic development, advanced studies on preclinical, clinical trials, bioavailability, permeability and administration of safe doses are necessary.

Keywords: Rubiadin, Rubia cordifolia, biosynthesis, physicochemical properties, anticancer, pharmacology 


\section{Graphical Abstract}

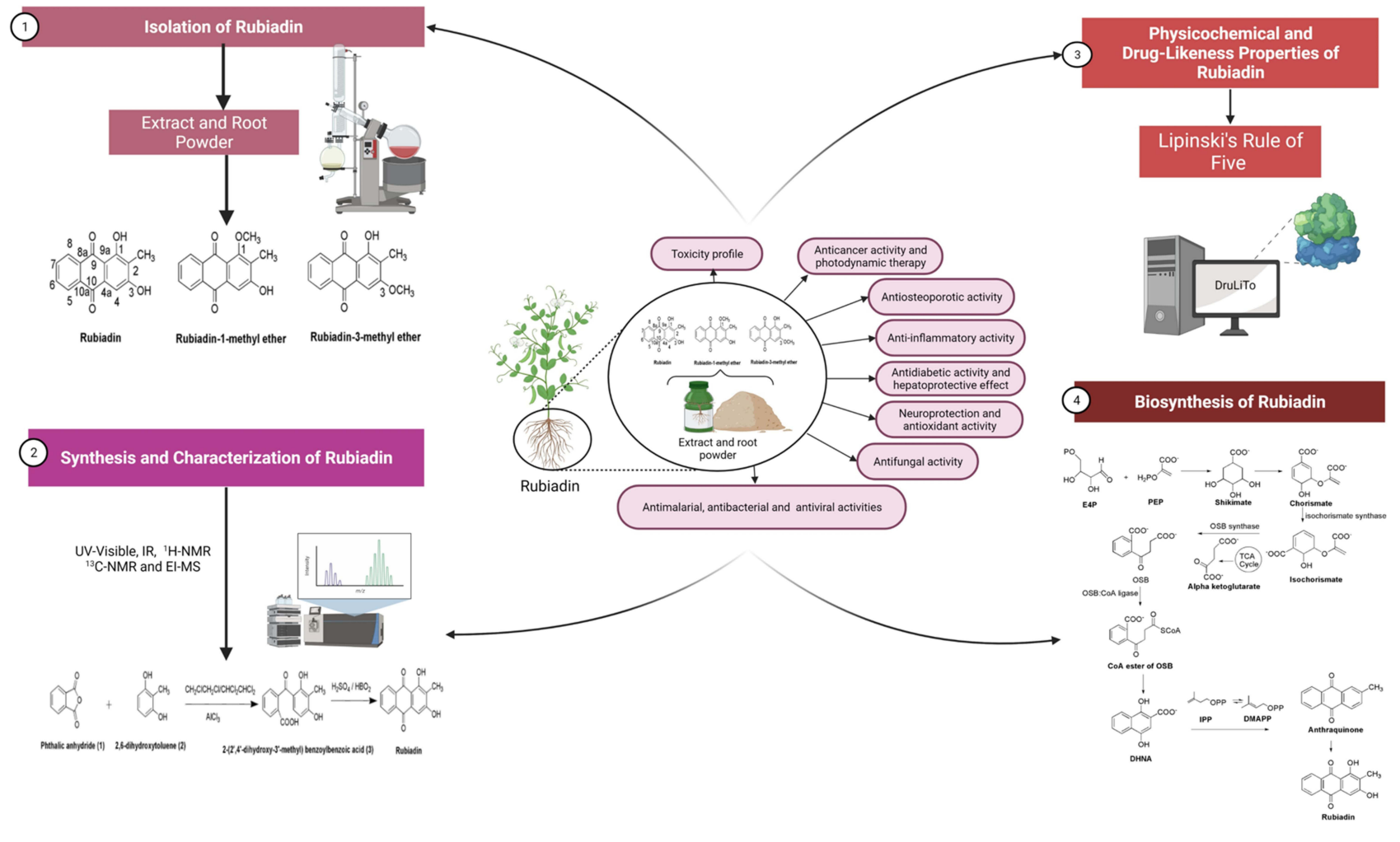

\section{Introduction}

The most important translational research endeavor that contributes to human health and well-being is drug discovery. All efforts involved in changing a drug-like molecule to a final licensed drug product for marketing by the necessary regulatory authorities are referred to as drug development. Identifying and screening of small molecules for their therapeutic benefits and biological properties are critical phases for drug discovery and development. Most of the well-known compounds in the world has been documented in a library that was created over a long period of time. Among those compounds or small molecules, most of them are derived from natural resources in the past. Currently, the researchers have access to a wide range of chemical substances and hundreds of thousands of novel compounds have also been discovered through high-throughput and combinatorial chemical processes. It remains to be identified which of these millions of molecules have the features that will allow them to become drugs.

Anthraquinones (AQs) are the biggest group of compounds with natural colors, with over 700 chemicals identified thus far. Plants provided approximately 200 of these chemicals, with the remaining coming from lichens and fungus. ${ }^{1,2}$ AQs are found in all plant parts including the roots, rhizomes, fruits and flowers with the majority produced from 9,10-anthracenedione. These compounds are also found in peas, cabbage, lettuce and beans. ${ }^{3}$ Due to their wide range of applications, AQs and their derivatives are among the most extensively utilized phytomolecules in the food and pharmaceutical industries. Studies have shown that AQs have been their reported for antioxidant, ${ }^{4}$ antitumor, ${ }^{5-9}$ anti-inflammatory, ${ }^{9,10}$ diuretic, ${ }^{9}$ antiarthritic, ${ }^{11}$ antifungal, ${ }^{12}$ antibacterial, ${ }^{13}$ and antimalarial ${ }^{14}$ activities. AQ derivatives are a very useful category in the search for anticancer medicines. AQ-based drugs such as doxorubicin, valrubicin, mitoxantrone, idarubicin, and epirubicin have been used successfully to treat hematological and solid malignancies. Therefore, the AQs core continues to be a potential scaffold for developing novel therapeutic candidates. $^{15}$

Rubiadin, a 1,3-dihydroxy-2-methyl anthraquinone (Figure 1), is primarily obtained from Rubia cordifolia Linn (R. cordifolia), which belongs to Rubiaceae family. It is an essential component in the Ayurvedic system of medicine in the treatment of various diseases. ${ }^{16}$ Rubiadin, which is 


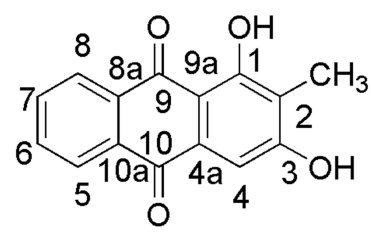

Rubiadin<smiles>COc1c(C)c(O)cc2c1C(=O)c1ccccc1C2=O</smiles>

Rubiadin-1-methyl ether<smiles>COc1cc2c(c(O)c1C)C(=O)c1ccccc1C2=O</smiles>

Rubiadin-3-methyl ether

Figure I Chemical structures of Rubiadin and its analogues. Note: Created with ChemDraw Ultra 8.0.

ubiquitous in many natural products, has sparked a lot of interest in recent years due to its excellent pharmacological effects including anticancer, antiosteoporotic, hepatoprotective, neuroprotective, anti-inflammatory, antidiabetic, antioxidant, antibacterial, antimalarial, antifungal, and antiviral activities. Nevertheless, despite its various therapeutic effects, it lacks a thorough and comprehensive review, to date. Hence, in the present review, the phytochemistry, biosynthesis and physicochemical properties of Rubiadin is summarized, with a particular focus on its biological activity. In order to strengthen this review, we have carried out molecular docking studies with selected proteins to prove its anticancer mechanism. It is hoped that the scientific evidence from this review can serve as a solid foundation for further research and provide important information for developing Rubiadin as a therapeutic agent and health product.

\section{Methods}

Relevant literature was collected from PubMed, ScienceDirect, Scopus and Google Scholar. The following keywords were used in the search: "Rubiadin" OR 1,3-dihydroxy-2-methyl anthraquinone OR 9,10-anthracenedione AND "Chemistry" OR "Biosynthesis" OR “in-vitro" OR “in-vivo" OR "Biological studies" OR "Pharmacological studies" OR "Toxicity" OR "Pharmacokinetics" OR "Pharmacodynamics" OR "Pharmacokinetics" OR "Pharmacodynamics". An initial screening was performed on studies that were not written in English or did not have any abstracts. The review's data was divided into two main categories: Rubiadin's chemical and biological properties. The scientific evidence gathered is summarized and incorporated following a thorough screening.

\section{Phytochemistry of Rubiadin Origin and Distribution}

Rubiadin is primarily isolated from the root of $R$. cordifolia, a Rubiaceae family. $R$. cordifolia is an important medicinal plant used in the Ayurvedic system of medicine in the treatment of a variety of diseases. ${ }^{16}$ Morinda officinalis (M. officinalis) which is another major source of Rubiadin $^{17}$ is a commonly used traditional Chinese medicine which has been used in China for many years. Additionally, Rubiadin is also found in a traditional medicine named Manjisthadi churna, which consists of lesser cardamom, used in the treatment of hyperlipidemia in India's Ayurvedic system of medicine and traditional medical practices. ${ }^{18}$ It is also found in some traditional Chinese medicines including Jia-Jian-Di-Huang-Yin-Zi decoction which is a seven-herb component consisting of Radix rehmanniae, Fructus corni, Radix morindae officinalis, Herba cistanches, Radix angelicae sinensis, Radix asparagi and Radix paeoniae alba ${ }^{19}$ as well as another decoction named $\operatorname{Er~Xian~}^{20}$ which is a six-herb component consisting of Herba epimedii, Radix morindae officinalis, Radix angelicae sinensis, Rhizoma anemarrhenae, Cortex phellodendri and Rhizoma curculiginis. Medicinal plants containing Rubiadin, Rubiadin-1-methyl ether (RBME) and Rubiadin-3-methyl ether are summarized in Table 1.

\section{Medicinal Uses of $R$. cordifolia}

$R$. cordifolia, also known as Indian madder or Manjistha, is a medicinal plant that grows in the forests of Pakistan, India, China, Korea, Japan and Mongolia. ${ }^{21}$ Based on ethnobotanical reports, its roots are used in the treatment of jaundice while the stems are used to treat snake bites and scorpion stings. It is also useful against diabetic foot ulcers. ${ }^{22}$ Traditionally, $R$. cordifolia is used for chronic pyrexia and puerperal fever, as well as a common medicine to alleviate heat and itching in eczema, psoriasis, herpes and scabies. When combined with honey, it is also deemed as effective against vitiligo. ${ }^{23}$ Other therapeutic effects include as an immunomodulator, analgesic, diuretic, gastroprotective, hepatoprotective, antioxidant, wound healing, nephroprotective and antiviral properties. ${ }^{24-27}$ 
Table I List of Medicinal Plants Containing Rubiadin

\begin{tabular}{|c|c|}
\hline Plant Source & References \\
\hline \multicolumn{2}{|l|}{ Rubiadin } \\
\hline Rubia cordifolia & Dosseh et $\mathrm{al}^{82}$; Tripathi et $\mathrm{al}^{28}$; Tripathi and Sharma ${ }^{61}$; Rao et $\mathrm{al}^{16}$; Shen et $\mathrm{al}^{83}$ \\
\hline Morinda officinalis & Liu et $\mathrm{al}^{84}$; Zhang et $\mathrm{al}{ }^{85}$; Zhao et $\mathrm{al}^{86}$; Shi et al ${ }^{17}$ \\
\hline Prismatomeris connata & Peng et $\mathrm{al}^{30}$ \\
\hline Heterophyllaea pustulata & $\begin{array}{l}\text { Montoya et } \mathrm{al}^{47} \text { Comini et } \mathrm{al}^{38} \text {; Vittar et } \mathrm{al}^{39} \text {; Marioni et } \mathrm{al}^{65} \text {; Micheloud et } \mathrm{al}^{48} \text {; Micheloud et } \mathrm{al}^{49} \text {; Cogno et } \mathrm{al}^{37} \text {; } \\
\text { Mugas et al }{ }^{37}\end{array}$ \\
\hline Rubia tinctorum & Schunck $^{88}$; Kawasaki et $\mathrm{a}^{89}$; Cuoco et $\mathrm{al}^{90}$; Cooksey ${ }^{91}$ \\
\hline Prismatomeris malayana & Tuntiwachwuttikul et al ${ }^{92}$ \\
\hline Lilium leucanthum & Khan et $\mathrm{al}^{64}$ \\
\hline Hymenodictyon excelsum & Rahman $^{93}$ \\
\hline Hedyotis capitellata & Ahmad et $\mathrm{al}^{94}$ \\
\hline Rubia peregrina & Usai and Marchetti9 ${ }^{95}$ \\
\hline Morinda umbellata & Chiou et $\mathrm{al}^{40}$ \\
\hline Prismatomeris fragrans & Kanokmedhakul et $\mathrm{al}^{42}$ \\
\hline Morinda citrifolia & Bussmann et $\mathrm{al}^{96}$ \\
\hline Morinda elliptica & Ali et $\mathrm{al}^{4 !}$ \\
\hline Prismatomeris sessiliflora & Likhitwitayawuid et al ${ }^{68}$ \\
\hline Ophiorrhiza shendurunii & Rajan et $\mathrm{al}^{97}$ \\
\hline Rennellia elliptica & Osman et $\mathrm{al}^{98}$ \\
\hline Knoxia valerianoides & Yuan and Zhao ${ }^{99}$; Yoo et al ${ }^{100}$; Zhao et al ${ }^{101}$ \\
\hline Blumea aromatica & Lan et al ${ }^{102}$ \\
\hline Prismatomeris tetrandra & Jiang et $\mathrm{al}^{103}$ \\
\hline Hedyotis diffusa & Huang et $\mathrm{al}^{104}$ \\
\hline Rhynchotechum vestitum & Liu et al $^{105}$ \\
\hline Swietenia mahagoni & Haque et al ${ }^{106}$ \\
\hline \multicolumn{2}{|l|}{ Rubiadin-I-methyl ether } \\
\hline Pentas schimperi & Mohr et $\mathrm{al}^{56}$ \\
\hline Morinda officinalis & $\mathrm{Li}$ et $\mathrm{al}^{107} ; \mathrm{He}$ et $\mathrm{al}{ }^{51} ;$ Zhang et $\mathrm{al}^{85}$ \\
\hline Morinda coreia & Chokchaisiri et al ${ }^{108}$ \\
\hline Heterophyllaea pustulata & Comini et $\mathrm{al}^{70} ;$ Cogno et $\mathrm{al}^{37}$ \\
\hline Prismatomeris fragrans & Kanokmedhakul et $\mathrm{al}^{42}$ \\
\hline Prismatomeris sessiliflora & Likhitwitayawuid et al ${ }^{68}$ \\
\hline Rennellia elliptica & Osman et $\mathrm{al}^{98}$ \\
\hline Prismatomeris tetrandra & Jiang et $\mathrm{al}^{103}$ \\
\hline Knoxia valerianoides & Zhao et al $^{101}$ \\
\hline Paederia scandense & Zou et al $\left.\right|^{109}$ \\
\hline Rhynchotechum vestitum & Liu et $\mathrm{al}^{105}$ \\
\hline Xanthophytum attopvensis & Li et al $\left.\right|^{110}$ \\
\hline Neonauclea calycina & Tosa et al' ${ }^{\prime \prime \prime}$ \\
\hline \multicolumn{2}{|l|}{ Rubiadin-3-methyl ether } \\
\hline Prismatomeris memecyloides & Khanh et al ${ }^{1 / 2}$ \\
\hline Craib & \\
\hline Morinda angustifolia & Chen et $\mathrm{al}^{1 / 3}$ \\
\hline Uvaria kurzii & Lv et al ${ }^{1 / 4}$ \\
\hline
\end{tabular}

\section{Isolation of Rubiadin}

The powdered root parts of $R$. cordifolia are extracted using a cold percolation in $50 \%$ aqueous ethanol following by a drying step using a rotary evaporator under a reduced pressure and a controlled temperature. In a separating funnel, the solvent-free extract is portioned with a $90 \%$ 
aqueous methanol and n-hexane. The n-hexane layer is removed and the aqueous-methanolic layer is subsequently dried and suspended in water for a further extraction step using chloroform (fraction 2) and n-butanol extractions in successive manner. Fraction 2 is chromatographed on a silica gel followed by an elution step with hexane, toluene, ethyl acetate and butanol (in order of increasing polarity) using varied solvent ratios. The column is further eluted with a toluene--hexane (1:1) combination, yielding a yellow solid. The solid is purified by numerous recrystallization processes using toluene and is further validated by a thin layer chromatography using toluene:ethyl acetate $(85: 15)$ as the mobile phase $\left(R_{f}=0.58\right)$. The spots are finally observed under UV irradiation. ${ }^{16,28}$

\section{Synthesis of Rubiadin}

In the first step, the condensation of phthalic anhydride (1) and 2,6-dihydroxytoluene (2) with $\mathrm{CH}_{2} \mathrm{ClCH}_{2} \mathrm{Cl} /$ $\mathrm{CHCl}_{2} \mathrm{CHCl}_{2}$ in the presence of aluminium chloride yielded 2-(2',4'-dihydroxy-3'-methyl) benzoylbenzoic acid (3). Then, in the second step, cyclization via dehydration of the compound $\mathbf{3}$ is performed in the presence of fused boric acid with concentrated sulphuric acid at $100{ }^{\circ} \mathrm{C}$ for 25 min to yield Rubiadin ${ }^{29}$ (Figure 2).

\section{Structural Characterization of Rubiadin}

A very detailed structural characterization of Rubiadin is given below based on the values obtained from spectroscopic methods including ultraviolet (UV), Fourier-transformed infrared (FTIR), ${ }^{1} \mathrm{H}$-nuclear magnetic resonance (NMR), ${ }^{13}$ C-NMR and EI-MS. ${ }^{30}$ The UV spectra of Rubiadin indicates a $\lambda$ max at $408 \mathrm{~nm}$ for $\mathrm{n}-\pi^{*}$ transition and at 279 and 251 for $\pi-\pi^{*}$ transitions. The IR spectra shows absorption bands at $3396(\mathrm{OH}), 2923,(\mathrm{C}-\mathrm{H}), 1661$ $(\mathrm{C}=\mathrm{O}$ non-chelated $)$ and at $1623,1589(\mathrm{C}=\mathrm{C}<$ aromatic $)$ representing the characteristic groups of Rubiadin. It also shows a molecular ion peak at $\mathrm{m} / \mathrm{z} 254.12$ in EI-MS and analysed for a molecular formula $\mathrm{C}_{15} \mathrm{H}_{10} \mathrm{O}_{4}$.
The ${ }^{1} \mathrm{H}-\mathrm{NMR}$ spectrum reveals the presence of a hydrogen-bonded hydroxyl group at $\delta 13.06(1 \mathrm{H}, \mathrm{s}]$ and another phenolic hydrogen at $\delta 11.22$ (1H, br.s.). The strong singlet for three protons at $\delta 2.02$ is due to the presence of a methyl group attached to the aromatic ring system while the singlet at $\delta 7.1$ for one proton is due to an aromatic proton in $\mathrm{H}-4$ position. On the other hand, the multiplet between $\delta 7.83$ and 7.88 for two protons are attributed to aromatic protons at H-6 and H-7 positions. A pair of doublet of doublets at $\delta 8.08(\mathrm{dd}, 1 \mathrm{H}, \mathrm{J}=1.5,7.5$ $\mathrm{Hz})$ and $8.12(\mathrm{dd}, 1 \mathrm{H}, \mathrm{J}=1.5,7.5 \mathrm{~Hz})$ are assigned to $\mathrm{H}-8$ and $\mathrm{H}-5$, respectively. In its ${ }^{13} \mathrm{C}-\mathrm{NMR}$ spectrum, there were 15 signals out of which two signals at $\delta 186.2$ and 181.78 are due to conjugated carbonyl carbons and are characteristic signals of anthraquinoid nucleus. The signal present in the upfield region at $\delta 8.09$ is due to the methyl carbon while the signal at $\delta 108.9$ is assigned to C-2 carbon. The two phenolic carbons appeared at $\delta 162.82$ and 162.46 where the carbon atoms adjacent to the phenolic carbons resonated at $\delta 107.35$ (C-4) and $117.3(\mathrm{C}$ 9a). The remaining signals at $\delta 134.54$ (C-8a), 134.44 (C10a), 132.98 (C-4a), 132.87 (C-6), 131.70 (C-7), 126.70 (C-5) and 126.37 (C-8) are characteristic signals off the unsubstituted aromatic ring of the AQ system. ${ }^{30}$

\section{Physicochemical and Drug-Likeness Properties of Rubiadin}

The physicochemical properties of Rubiadin are mainly obtained from PubChem ${ }^{31}$ and other reliable databases such as DruLiTo. Certain physicochemical features allow a molecule to be converted into a drug-like molecule: 1) molecule should be small enough to be transported throughout the body, 2) hydrophilic enough to dissolve in the blood stream, 3) lipophilic enough to cross fat barriers within the body and 4) contain enough number of polar groups to bind to a receptor but not too many which leads elimination too quickly from the body via urine to exert the therapeutic effect (Table 2). The drug-like properties (molecular weight, H-bond donors, H-bond acceptors, log<smiles>O=C1CC(=O)c2ccccc21</smiles>

Phthalic anhydride (1)

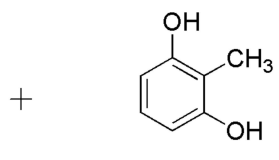

2,6-dihydroxytoluene (2)

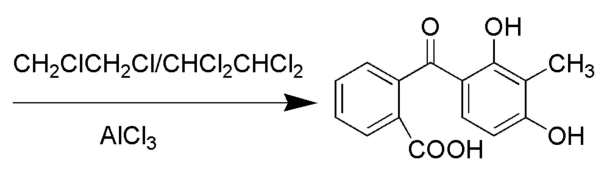

2-(2',4'-dihydroxy-3'-methyl) benzoylbenzoic acid (3)

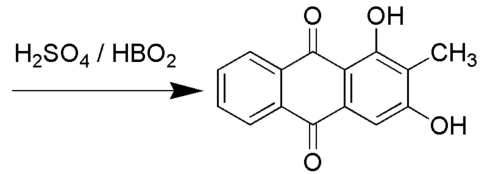

Rubiadin

Figure 2 Synthesis of Rubiadin. Note: Created with ChemDraw Ultra 8.0. 
Table 2 Computed Physicochemical Properties of Rubiadin

\begin{tabular}{|c|c|}
\hline Property & Value/Result \\
\hline Common name & Rubiadin \\
\hline Synonyms & I,3-Dihydroxy-2-methylanthracene-9, I0-dione; 9, I0-anthracenedione-1,3-dihydroxy-2-methyl-Rubiadine \\
\hline Category & Anthraquinone \\
\hline IUPAC name & I,3-Dihydroxy-2-methylanthracene-9,10-dione \\
\hline Canonical SMILES & $\mathrm{CCl}=\mathrm{C}(\mathrm{C}=\mathrm{C} 2 \mathrm{C}(=\mathrm{ClO}) \mathrm{C}(=\mathrm{O}) \mathrm{C} 3=\mathrm{CC}=\mathrm{CC}=\mathrm{C} 3 \mathrm{C} 2=0) \mathrm{O}$ \\
\hline Molecular formula & $\mathrm{C}_{15} \mathrm{H}_{10} \mathrm{O}_{4}$ \\
\hline Molecular weight & $254.06 \mathrm{~g} / \mathrm{mol}$ \\
\hline Hydrogen bond donors & 2 \\
\hline Hydrogen bond acceptors & 4 \\
\hline Rotatable bonds & 0 \\
\hline $\log P$ (partition coefficient value) & 0.809 (Predicted) \\
\hline Molar refractivity & 68.83 \\
\hline Topological polar surface area & $74.6 \AA^{2}$ \\
\hline Percent composition & $\mathrm{C}: 0.709, \mathrm{H}: 0.040, \mathrm{O}: 0.252$ \\
\hline XLogP3-AA & 3.1 \\
\hline Molar mass & $254.05790880 \mathrm{Da}$ \\
\hline Monoisotopic mass & $254.05790880 \mathrm{Da}$ \\
\hline Heavy atom count & 19 \\
\hline Formal charge & 0 \\
\hline Complexity & 405 \\
\hline Isotope atom count & 0 \\
\hline Atom stereocenter count & 0 \\
\hline Bond stereocenter count & 0 \\
\hline Covalently bonded unit count & I \\
\hline Canonicalized & I \\
\hline Melting point & $290^{\circ} \mathrm{C}$ \\
\hline Boiling point & $527^{\circ} \mathrm{C}$ \\
\hline Appearance & Yellow needle shape \\
\hline Solubility & Ethyl acetate \\
\hline Density & $1.5 \mathrm{~g} / \mathrm{mL}$ \\
\hline Pka & 6.350 \\
\hline Molar volume & 215.17 \\
\hline Molecular polar surface area & $74.6 \AA^{2}$ \\
\hline Molecular 3D-polar SASA & 419.12 \\
\hline Molecular SASA & 411.10 \\
\hline Molar refraction & $72.28 \mathrm{~cm}^{3} / \mathrm{mol}$ \\
\hline
\end{tabular}

$\mathrm{P}$ value and rotatable bonds) as described in Lipinski's rule of five $\mathrm{e}^{32}$ are calculated using Biovia Discovery studio 19.0. Any drug-like compound should have 1) a molecular weight of 500,2$)$ a partition coefficient $(\log \mathrm{P})$-value of 5 , 3) H-bond donors of 5,4) H-bond acceptors of 10 and 5) rotatable bonds of 10 according to Lipinski's rule of five. Since compounds that do not break Lipinski's rule of five may have improved folding, polarity and molecular size, the drug-like molecules are assumed to have the predicted therapeutic benefits. $^{33}$ The objective of the suggested method is to deliver primary evidence defining the potential physical properties of the compounds, rather than serving as a rigid screening criteria in itself, since Lipinski's rule of five is an effective and valid guide for forecasting the potential for oral exposure to enhanced chemical compounds. Overall, Rubiadin appears to match all five of Lipinski's drug-likeness criteria (Table 2). According to the data acquired from DruLiTo software, Rubiadin also passed the Ghose filter, Veber's rule, bloodbrain barrier (BBB) likeness rule, Unweighted Quantitative Estimate of Drug-likeness (QED), and Weighted QED, but failed the CMC-50 like rule and 


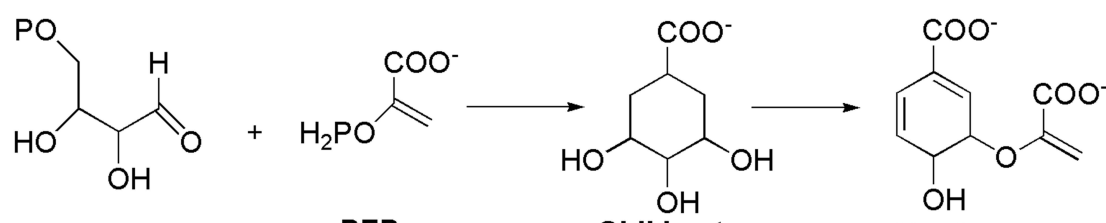

E4P

PEP

Shikimate

Chorismate isochorismate synthase<smiles>O=C([O-])CCC(=O)c1ccccc1C(=O)[O-]</smiles>

OSB

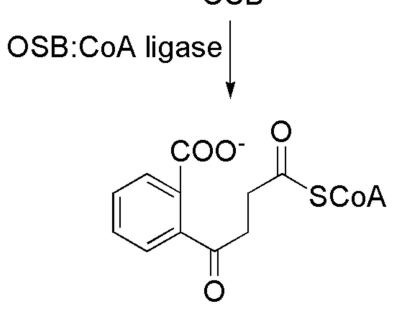

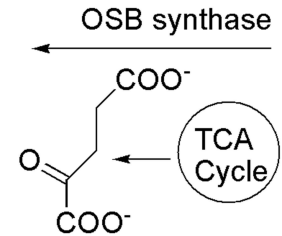

Alpha ketoglutarate<smiles>C=C(OC1C=CC=C(C(=O)[O-])C1O)C(=O)[O-]</smiles>

Isochorismate<smiles>CC(C)(C)O[Mg]C(=O)OCc1c(C(=O)[O-])cc(O)c2ccccc12</smiles>

DHNA

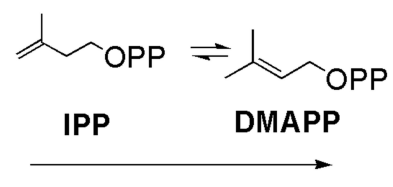<smiles>Cc1ccc2c(c1)C(=O)c1ccccc1C2=O</smiles>

Anthraquinone

$\downarrow$<smiles>Cc1c(O)cc2c(c1O)C(=O)c1ccccc1C2=O</smiles>

Rubiadin

Figure 3 Biosynthesis of Rubiadin.

Note: Created with ChemDraw Ultra 8.0.

MDDR like rule. All of the above findings indicate that it is a good potential therapeutic agent for a variety of disorders.

\section{Biosynthesis of Rubiadin}

AQs are derived from a variety of precursors and pathways in nature. Two biosynthesis pathways have been established: 1) the polyketide and 2) the chorismate/o-succinylbenzoic acid pathways, despite the fact that their biosynthetic processes remain unknown. Rubiadin is made by combining phosphophenol pyruvate (PEP) with erythrose-4-phosphate (E4P) to produce chorismate and isochorismate, which are then transformed to $o$-succinylbenzoate (OSB) in the presence of -ketoglutarate (Figure 3). Rings A and B of Rubiadin are formed through the synthesis of 1,4-dihydroxy-2-naphthoic acid (DHNA) by a ring closure of OSB-CoA. Prenylation of the DHNA results in naphthoquinol or naphthoquinone, which is involved in the synthesis of ring C. Isopentenyl pyrophosphate (IPP), which can be generated from mevalonate (MVA) or 2-C-methyl-D-erythritol 4-phosphate (MEP), is required for the biosynthesis of $\mathrm{AQs}$, including Rubiadin (Figure 4). In the late stages of biosynthesis, most AQs in the Rubiaceae undergo different alterations owing to hydroxylation or methylation, in which groups like as hydroxy and methyl groups are added to Rubiadin's ring C. ${ }^{34}$ 
MVA pathway

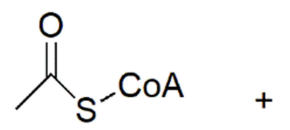

Acetyl CoA
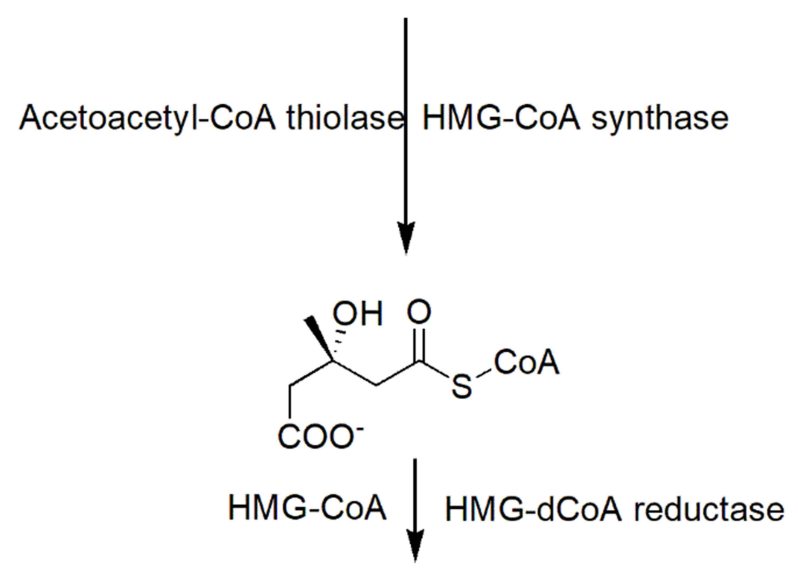

$\overbrace{\mathrm{COO}^{-}}^{\mathrm{OH}} \mathrm{OH}$

\section{Mevalonate}

$\downarrow$

$\downarrow$ Mevalonate kinase<smiles>C[C@](O)(CCO[PH2+])CC(=O)[O-]</smiles>

Mevalonate-5-pyrophosphate

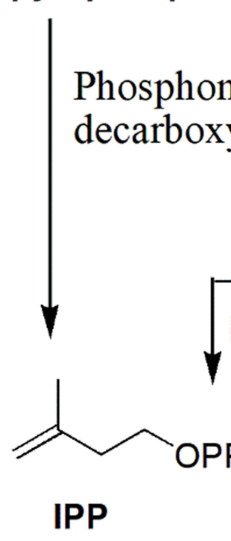

MEP pathway<smiles>CC(=O)C(=O)O</smiles>

Pyruvate G3P

1-deoxy-D-xylulose- 5-phosphate synthase<smiles>CC(=O)C(O)C(O)C[Po]</smiles>

DXP

1-deoxy-D-xylulose-5-phosphate reductoisomerase<smiles>CC(O)(CO)C(O)C[Po]</smiles>

MEP

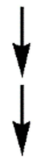<smiles>CC(CO)(OP(=O)([O-])OP(=O)([O-])O)C(O)CO</smiles>

MECP

Figure 4 MVA and MEP pathways for the synthesis of IPP. Note: Created with ChemDraw Ultra 8.0. 

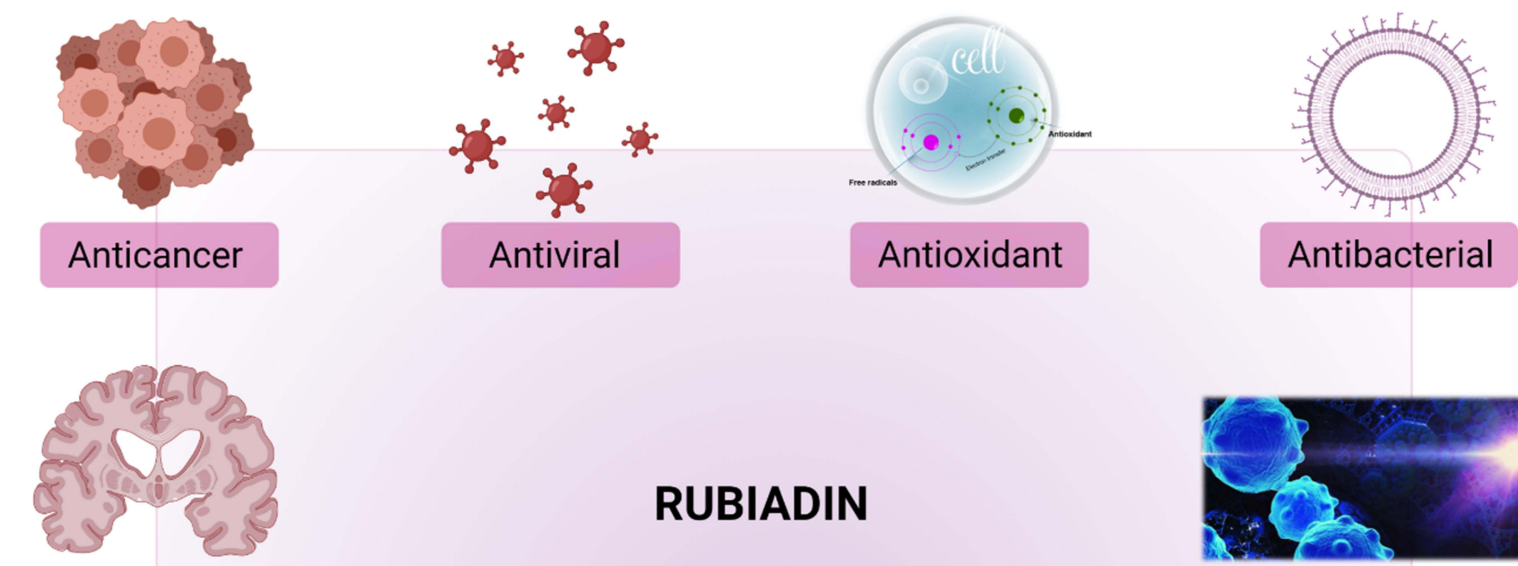

\section{RUBIADIN}

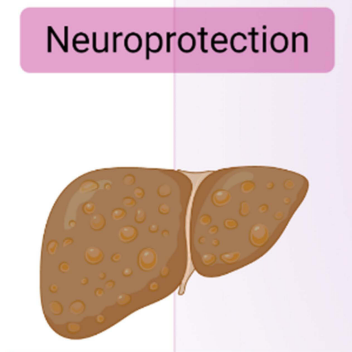

Hepatoprotection
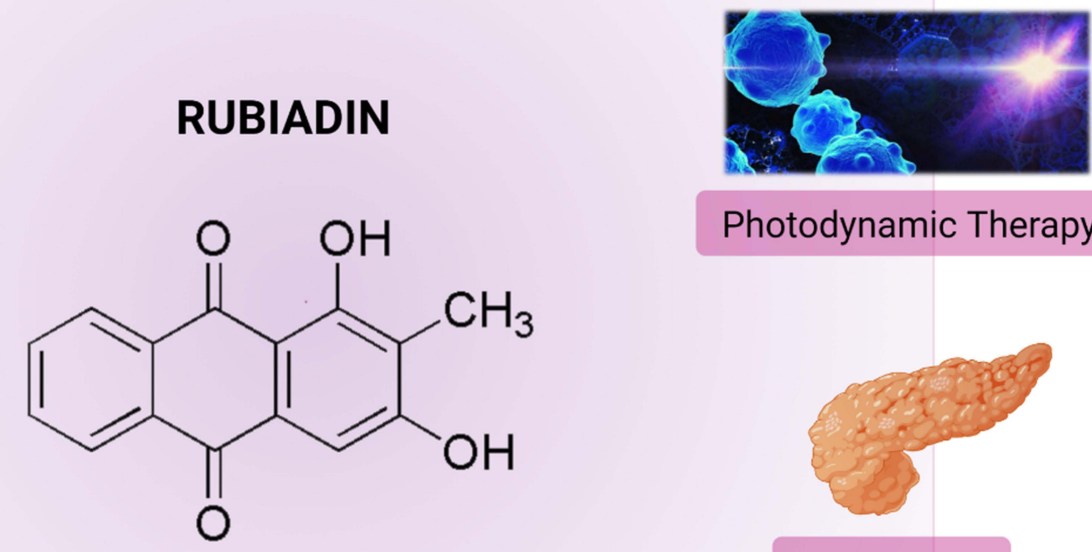

Photodynamic Therapy

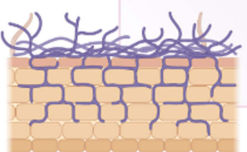

Antifungal

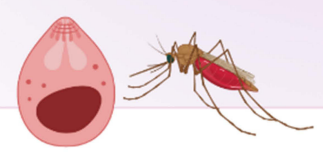

Antimalarial

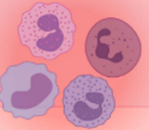

Anti-inflammatory

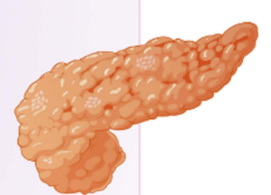

Antidiabetic

Figure 5 Biological properties and therapeutic potential of Rubiadin.

Note: Created with BioRender.com.

\section{Biological Activities of Rubiadin}

Rubiadin has been reported to possess many biological activities (Figure 5) as summarized below.

\section{Toxicity Profile}

One of the latest acute toxicity study reported that oral administration of Rubiadin (100, 200, 500 and $1000 \mathrm{mg} /$ $\mathrm{kg}$ ) to Swiss albino mice using staircase/up and down method showed no significant toxicity. ${ }^{35}$ Furthermore, mice given an aqueous extract of $R$. cordifolia and $R$. tinctorum (Rubiadin as one of the principal constituents) for 14 days indicated that the highest acceptable doses were $3500 \mathrm{mg} / \mathrm{kg}$ and $5000 \mathrm{mg} / \mathrm{kg}$, respectively. In another study, both sexes of mice were administered with $R$. cordifolia root extract mixed in their diet $(0-5 \%)$ for 90 days with no clinical signs of toxicity seen, although there were some changes in kidney and epidermal vaginal cyst in some animals based on histological analysis. Overall, the findings indicate that Rubiadin is safe at the investigated dose levels (Figure 6).

\section{Anticancer Activity and Photodynamic Therapy}

AQs have long been believed to have anticancer properties, acting primarily through DNA damage, cycle arrest and apoptosis. ${ }^{36}$ Very recently, Cogno et al ${ }^{37}$ evaluated the photoactivity of Rubiadin on monolayers and multicellular tumor spheroids following a photodynamic therapy. Rubiadin showed photosensitizing ability on monoculture of colon cancer cells (SW 480) at low concentration where necrosis has occurred. In addition, Comini et $\mathrm{al}^{38}$ 
Toxicity profile, anticancer activity and photodynamic therapy of rubiadin

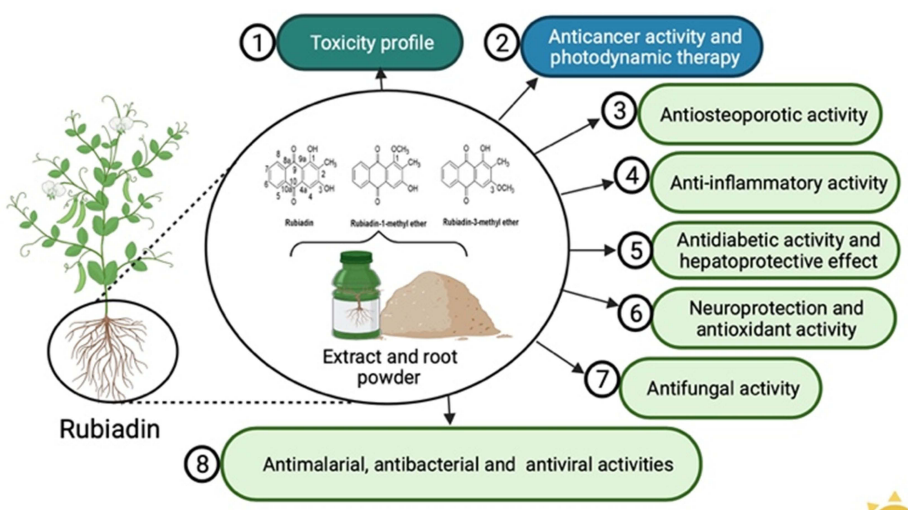

(1) Toxicity profile

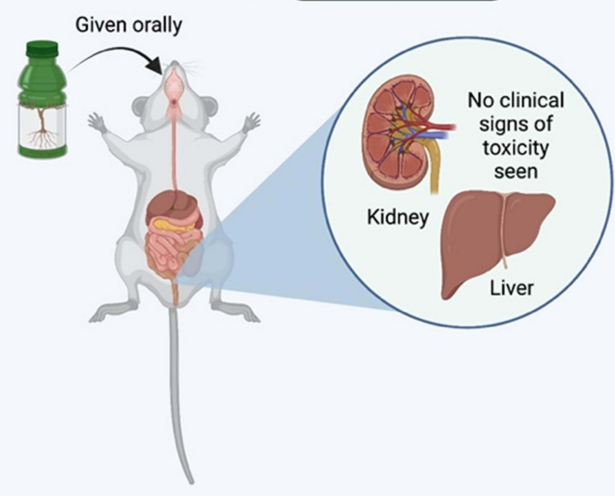

\section{(2) Anticancer activity and photodynamic therapy}

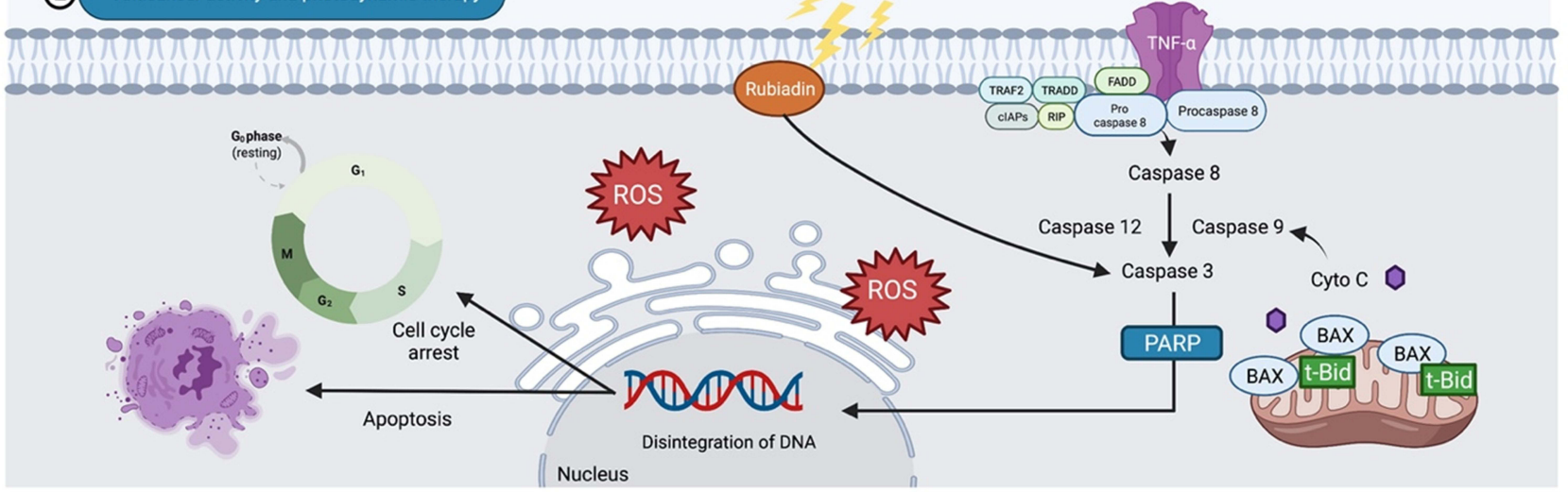

Figure 6 Rubiadin's toxicity profile, anticancer activity, and photodynamic therapy. In the toxicity study, oral administration of rubiadin showed no clinical signs of toxicity seen indicating that the biochemical compound is safe at certain investigated dose levels. Through favorable photosensitizing ability of rubiadin, it can act as an anticancer by acting primarily through DNA damage, cycle arrest and apoptosis and be used in photodynamic therapy.

Note: Created with BioRender.com.

Abbreviations: TNF- $\alpha$, tumor necrosis factor alpha; TRAF2, TNF receptor-associated factor 2; clAPs, cellular inhibitors of apoptosis; TRADD, TNFRI-associated death domain protein; FADD, Fas-associated death domain protein; RIP, ribosome-inactivating protein; Bax, BCL2 associated X, apoptosis regulator; t-Bid, truncated Bid; Cyto C, cytochrome complex; PARP, poly (ADP-ribose) polymerase; ROS, reactive oxygen species.

investigated the potential role of Rubiadin and RBME as phototoxic agents against human breast cancer using MCF-7c3 cells. At $100 \mu \mathrm{M}$ and a light exposure of $1 \mathrm{~J} /$ $\mathrm{cm}^{2}$, both Rubiadin and RBME showed considerable photocytotoxicity on cancer cells. The observed cellular death by the photoactivated Rubiadin and RBME were closely related to a singlet oxygen production, with decreased cell viability in relation to tumor cell uptake. Subsequently, another study by Vittar et $\mathrm{al}^{39}$ revealed that Rubiadin exhibited significant photocytotoxicity on human cancer cells (MCF-7c3) in a concentration-dependent manner. Additionally, biochemical analysis revealed the involvement of caspase-3, PARP cleavage and DNA fragmentation in Rubiadin-induced apoptosis (Figure 6).

In addition to the above studies, Rubiadin also exhibited significant cytotoxicity against HepG2 cells, with minimum inhibitory concentration $\left(\mathrm{IC}_{50}\right)$ values of $3.6,4.4$ and 4.8 $\mu \mathrm{M}$, respectively. ${ }^{40}$ It also conferred cytotoxicity towards the CEM-SS (T-lymphoblastic leukaemia), MCF-7 (breast carcinoma) and HeLa (cervical carcinoma) cell lines with $\mathrm{IC}_{50}$ of 3,10 and $>30 \mu \mathrm{g} / \mathrm{mL}$, respectively. ${ }^{41}$ In another study, Rubiadin and RBME exhibited significant cytotoxicity against NCI-H187 cells, with $\mathrm{IC}_{50}$ values of 14.2 and $4.5 \mu \mathrm{g} / \mathrm{mL}$, respectively, ${ }^{42}$ indicating its potential anticancer effects.

However, madder color, a food coloring made from Rubia tinctorum roots, has been shown to cause cancer in rats' kidneys and liver. In F344 rats, treatment with Rubiadin $(0.04 \%)$ for 23 weeks enhanced atypical renal tubules/hyperplasias and induced renal cell adenomas and carcinomas. Additionally, Rubiadin enhanced glutathione S-transferase placental form-positive liver cell foci and 
major intestinal dysplasias thus suggesting that Rubiadin enhances renal preneoplastic lesions, with a weaker effect on dysplasia. Additionally, Rubiadin may also target the liver and large intestine, implying that it plays a significant role in madder color-induced carcinogenicity. ${ }^{43}$ Based on another study by the same researcher, Rubiadin is a potent carcinogenic metabolite of madder color, targeting proximal tubule cells in the outer medulla, ${ }^{44}$ although oxidative stress increased by lucidin-3-O-primeveroside or alizarin may also be involved in renal carcinogenesis by madder color.

From another study, the excretion of lucidin and rubiadin was observed in rats following administration of lucidinprimeveroside (Lup). Lup was reduced to Rubiadin primeveroside which in turn, was hydrolyzed to Rubiadin, when treated with rat liver extract and nicotinamide adenine dinucleotide phosphate (NADPH). Rubiadin was more potent than lucidin but has similar effect to the positive control 7,12-di-methylbenz[ $\alpha]$ anthracene in the unscheduled DNA synthesis experiment in primary rat hepatocytes. The uptake of the AQs glycosides alizarinprimeveroside (Alp) and Lup results in the production of a rodent carcinogen 1-hydroxyanthraquinone, as well as the highly genotoxic compounds lucidin and Rubiadin. ${ }^{45}$

The latest scientific evidence has demonstrated that novel AQs can inhibit cancer by paraptosis, autophagy, radiosensitization, thus overcoming chemoresistance. ${ }^{36}$ However, scientists are still far from having a full understanding on the anticancer properties of Rubiadin, since some report mentioned it is also carcinogenic. ${ }^{43,44}$ Thus, more in vivo and preclinical research are needed to fully understand its apparent potential in preventing and treating a variety of malignancies.

Although photoactivity is known for decades, only recently that it resurfaced as a potential therapy option for cancer and microbial diseases. Its key innovative component is light as the external factor since light can activate drugs locally, besides having a high level of selectivity and conferring minimal side effects. ${ }^{46}$ Animals that ingest the aerial parts of $H$. pustulata show a classic primary photoensitization reaction, which is clinically characterized as dermatitis and, in severe cases, blindness. H. pustulata grows mainly in the Andes region of northwest Argentina. Rubiadin, a major compound in H. pustulata, is characterized as either a Type I or II photosensitizer, depending on its physicochemical features. Oral administration of Rubiadin can reproduce natural in experimental animals.
The presence of Rubiadins in the serum was identified and quantified in the skin of experimental animals using high performance liquid chromatography. ${ }^{47}$ Since $H$. pustulata contains photosensitizing AQs such as Rubiadin and soranjidiol, the plant can cause dermal lesions through photosensitization. $^{48}$ Another study reported that Rubiadin and soranjidiol should be administered between 24 and 72 hours after $H$. pustulata ingestion, in order to coincide with the time when clinical indications are more noticeable. The clinical findings were validated for the presence of Rubiadin and soranjidiol in sera, although Rubiadin and soranjidiol were absent in skin samples. Finally, toxicological investigations on both compounds are important, since several recent researches have suggested that they could be used in photodynamic therapy. ${ }^{49}$

Rubiadin confer a favorable response to photodynamic therapy and therefore should be further examined. Additionally, any interaction between its use in reversing drug-resistant phenotypes and its photosensitizing effect should be further investigated.

\section{Antiosteoporotic Activity}

Low bone mineral density (BMD) and micro-architectural deterioration of bone tissue are characteristic of osteoporosis, resulting in increased bone fragility and fracture risk. ${ }^{50} \mathrm{He}$ et $\mathrm{al}^{51}$ investigated the in vitro effect of RBME on osteoclasts and the underlying mechanism. RBME inhibited the expression of osteoclast-related proteins such as nuclear factor of activated T-cells cytoplasmic 1 (NFATc1), cellular oncogene Fos (c-Fos), matrix metallopeptidase 9 (MMP-9) and cathepsin $\mathrm{K}$ (CtsK), as determined by Western blot analyses. RBM also reduced the nuclear translocation of p65 and inhibited the phosphorylation of nuclear factor kappa B (NF-kB) p65 and the degradation of nuclear factor of kappa light polypeptide gene enhancer in B-cells inhibitor alpha $(\mathrm{I} \kappa \mathrm{B} \alpha)$ indicating that RBME may be a promising agent for the prevention and treatment of bone disorders characterized by excessive bone resorption, due to its ability to inhibit osteoclastic bone resorption by blocking the NF- $\mathrm{BB}$ pathway (Figure 7).

Bao et $\mathrm{al}^{52}$ investigated the in vitro effects of Rubiadin on bone resorption activity and its mechanism on osteoclasts derived from rat bone marrow cells. In a co-culture system of osteoblasts and bone marrow cells, Rubiadin reduced the formation of bone resorption pits, the number of multinucleated osteoclasts and the activity of tartrate resistant acid phosphates (TRAP) and cathepsin K. Additionally, Rubiadin increased the death of osteoclasts caused by macrophage colony stimulation factor (M-CSF) and receptor activator of 
Antiosteoporotic and anti-inflammatory activities of rubiadin

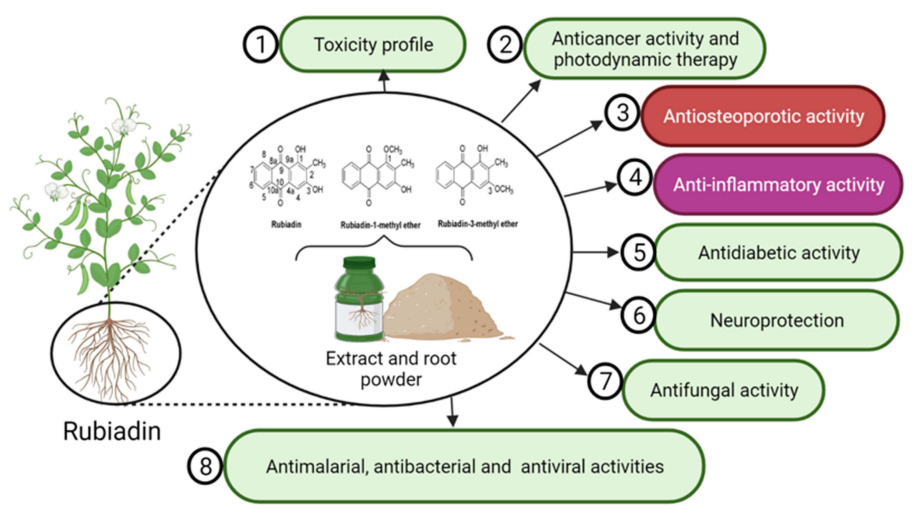

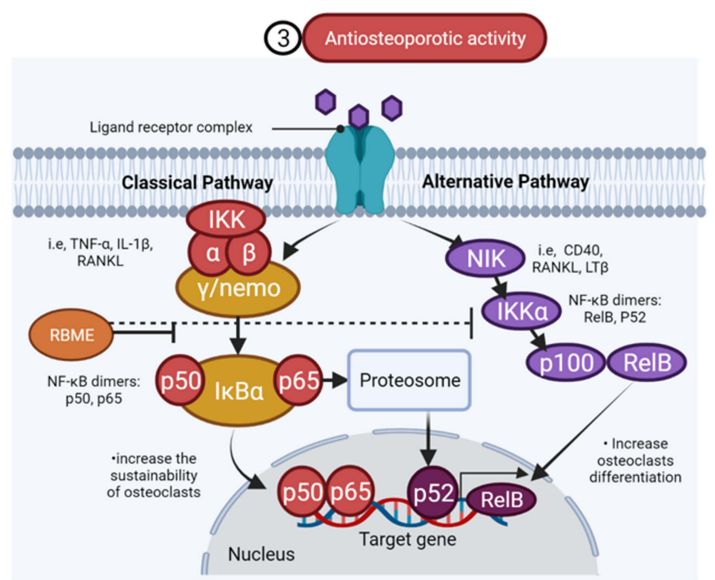

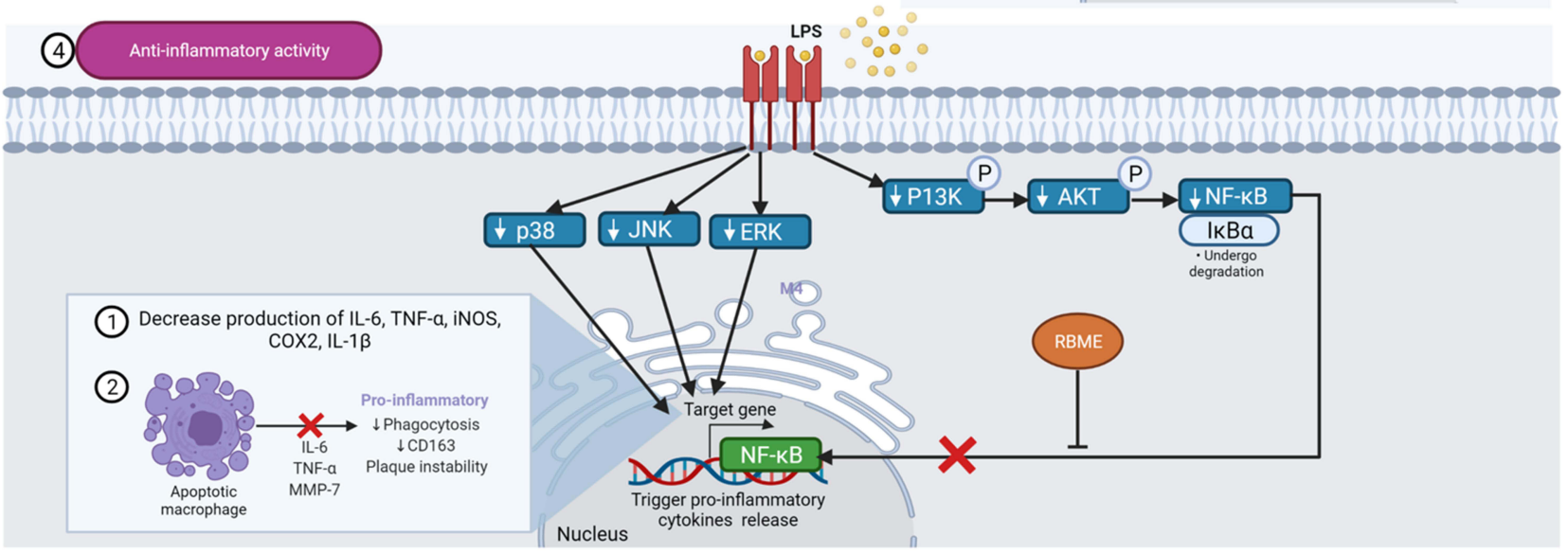

Figure 7 Antiosteoporotic and anti-inflammatory activities of rubiadin. Inhibition of nuclear factor kappa B (NF-kB) phosphorylation and degradation of nuclear factor of kappa light polypeptide gene enhancer in B-cells inhibitor alpha $(1 \kappa B \alpha)$ by RBME suggests that it could be used to treat bone disorders characterized by excessive bone resorption. RBME demonstrated anti-inflammatory activity by decreasing pro-inflammatory markers while increasing the apoptotic rate of macrophages.

Note: Created with BioRender.com.

Abbreviations: TNF- $\alpha$, tumor necrosis factor alpha; IL-IB and 6, interleukin I beta and 6; RANKL, receptor activator of nuclear factor kappa-B ligand; IKK $\gamma /$ NEMO, nuclear factor-kappa B essential modulator; IkB $\alpha$, nuclear factor of kappa light polypeptide gene enhancer in B-cells inhibitor, alpha; IKK $\alpha$, inhibitory kappa B kinase $\alpha$; NF-kB, nuclear factor kappa-light-chain-enhancer of activated B cells; NIK, NF- $\kappa B$ inducing kinase; CD40 \& 163, cluster of differentiation 40 and I63; LTB, lymphotoxin beta; RelB, RELB proto-oncogene, NF-KB subunit; ERK, extracellular signal-regulated kinase; JNK, c-Jun N-terminal kinase; PI3K, phosphoinositide 3-kinases; AKT, protein kinase B/ AKT; iNOS, inducible nitric oxide synthase; COX2, cyclooxygenase-2; MMP-7, matrix metalloproteinase-7.

NF- $\kappa$ B ligand in bone marrow cells (RANKL). Rubiadin also 1) increased the ratio of osteoprotegerin (OPG), RANKL mRNA and protein expression in osteoblasts; 2) interfered the c-Jun N-terminal kinase (JNK) and NF- $\kappa \mathrm{B}$ signaling pathways; and 3) reduced the expression of calcitonin receptor and carbonic anhydrase/II in osteoclasts induced from bone marrow cells with M-CSF and RANKL in osteoclasts. Overall, the findings suggest that Rubiadin may be a potential inhibitor for bone resorption. ${ }^{52}$ Since RBME can inhibit osteoclast TRAP activity and bone resorption, it may be useful against osteoporosis. ${ }^{53}$

Xia et $\mathrm{al}^{54}$ investigated the protective effect of $M$. officinalis on glucocorticoid-induced osteoporosis (GIOP)-modelled rats and osteoblasts. Eight weeks after dexamethasone (DEX) injection and $M$. officinalis treatment in female rats aged 12 weeks, the BMD, micro-architecture of the trabecular bone, serum level of bone metabolism markers and urine metabolomics were assayed in vivo. The cultured osteoblasts were injured with DEX before the effects of $M$. officinalis, RBME on osteoblastic proliferation, differentiation and mineralization were investigated in vitro. $M$. officinalis increased BMD, improved the micro-architecture and intervened with bone metabolism via regulating alkaline phosphatase (ALP), tartrate resistant acid phosphatase (TRAP) and c-terminal telopeptides of type I collagen (CTX-I) levels. The in vitro experiment showed that $M$. officinalis and RBME increased the cell proliferation, ALP activity and enhanced extracellular matrix mineralization in DEXinjured osteoblasts. ${ }^{54}$ Additionally, another study 
demonstrated that multiple ingredients in a traditional Chinese medicine decoction named Er-Xian that included Rubiadin has anti-osteoporotic activity. ${ }^{20}$ Although the data indicated that Rubiadin has action against bone tissue, more efficient and reliable bioassays should be urgently developed for thorough investigation of its antiosteoporotic mechanism before human clinical trials.

\section{Anti-Inflammatory Activity}

Inflammation is a set of activities that occur in response to tissue damage associated with oxidative stress or other factors that initiate repair processes including as extracellular matrix remodeling and fibrosis. ${ }^{55}$ Mohr et al ${ }^{56}$ investigated the anti-inflammatory efficacy of RBME using an in vitro model of RAW 264.7 macrophages induced by lipopolysaccharide (LPS). The results indicated that RBME decreased the levels of pro-inflammatory markers such as nitric oxide (NOx), interleukin (IL)-6 and IL-1 with increased in macrophage apoptotic rate seen (Figure 7). The anti-inflammatory effects of Rubiadin-1methyl ether was also investigated using an in vivo acute lung injury (ALI) induced by LPS ( $5 \mathrm{mg} / \mathrm{kg}$, P.O.) by a similar group of researchers. Administration of RBME (3, 10 and $30 \mathrm{mg} / \mathrm{kg}$, P.O.) decreased leukocyte infiltration, fluid leakage, NOx, IL-6, IL-12p70, interferon gamma (IFN- $\gamma$ ), tumour necrosis factor $\alpha(\mathrm{TNF}-\alpha)$ and monocyte chemoattractant protein-1 (MCP-1) levels as well as MPO activity (Mohr et al, 2019). RBME also enhanced the levels of IL-10 in the bronchoalveolar lavage fluid (BALF). On the other hand, Rubiadin's anti-inflammatory activity and potential mechanism of action, has yet to be confirmed and requires further research.

\section{Antidiabetic Activity}

Mujeeb et $\mathrm{al}^{57}$ evaluated the effectiveness of Rubiadinloaded niosomes (RLN) in treating diabetic nephropathy (DN) that is induced by streptozotocin-nicotinamide (STZNA) in Wistar rats. In STZ-NA-induced DN rats, oral administration of RLN (100 and $200 \mathrm{mg} / \mathrm{kg} /$ week) markedly reduced blood glucose levels. Furthermore, RLN formulation significantly reduced urea, uric acid and creatinine levels while improving lipid, thiobarbituric acid reactive substances (TBARS), glutathione (GSH), superoxide dismutase (SOD) and catalase (CAT) levels in DN rats (Figure 8) ${ }^{57}$ Nevertheless, other than this study, no other evidence of Rubiadin's anti-diabetic effectiveness has been found indicating that further studies are required to confirm Rubiadin's anti-diabetic properties.

\section{Hepatoprotective Activity}

The hepatoprotective effect of Rubiadin was tested against carbon tetrachloride $\left(\mathrm{CCl}_{4}\right)$-induced liver injury in rats. ${ }^{16}$ In $\mathrm{CCl}_{4}$-induced rats $(1 \mathrm{~mL} / \mathrm{kg}$, i.p $)$, the co-treatment of Rubiadin (50, 100 and $200 \mathrm{mg} / \mathrm{kg}$, P.O.) for 2 weeks restored serum glutamic oxaloacetic transaminase, glutamate pyruvate transaminase, alkaline phosphatase (ALP), $\gamma$-glutamyltransferase $(\gamma$-GT), glutathione S-transferase and glutathione reductase levels to normal. Rubiadin also inhibited the development of hepatic malondialdehyde and the depletion of reduced glutathione level in the liver of $\mathrm{CCl}_{4}$-intoxicated rats in a dose-dependent manner, thus strongly suggesting that Rubiadin has a hepatoprotective effect against $\mathrm{CCl}_{4}$-induced hepatic damage in rats (Figure 8). ${ }^{16}$ However, more research is needed in future to confirm Rubiadin's hepatoprotective potential especially in models that greatly mimic humans liver disease.

\section{Neuroprotection}

The significant reduction in the onset of jerks and Straub tail along with a significant increase in onset of clonus and extensor were observed with pre-treatment of Rubiadin suspension (100 and $250 \mathrm{mg} / \mathrm{kg}$, P.O.) for 3 days to the pentylene tetrazole (PTZ)-induced $(80 \mathrm{mg} / \mathrm{kg}$, i.p.) clonictonic convulsions in mice. Pre-treatment of Rubiadin suspension also significantly reduced the hind limb extension in maximal electro shock (MES)-induced seizures induced by delivering an electroshock at $50 \mathrm{~mA}$ using an electroconvulsometer through a pair of ear clip electrodes in Swiss albino mice. Rubiadin suspension $(250 \mathrm{mg} / \mathrm{kg})$ conferred some anticonvulsant effects in both MES- and PTZinduced epileptic seizure models ${ }^{35}$ overall indicating that Rubiadin is a potential neuroprotectant (Figure 8). The above study is a novel platform for testing Rubiadin against neurodegenerative disorders including Alzheimer's, Parkinson's and Huntington's disease.

\section{Antioxidant Activity}

The antioxidant effects of AQs including Rubiadin are well known. ${ }^{58-60}$ Rubiadin inhibits lipid peroxidation as induced by ferrous sulphate and $t$-butylhydroperoxide especially in $\mathrm{Fe}^{2+}$-induced lipid peroxidation (Figure 8). Rubiadin's antioxidant properties were comparatively higher than ethylenediaminetetraacetic acid (EDTA), tris, mannitol, vitamin $\mathrm{E}$ and $p$-benzoquinone. ${ }^{28}$ Based on a follow-up study by Tripathi and Sharma, ${ }^{61}$ Rubiadin inhibits lipid peroxidation in a dose-dependent manner. Apart 
Antidiabetic, hepatoprotective, neuroprotection and antioxidant activities of rubiadin

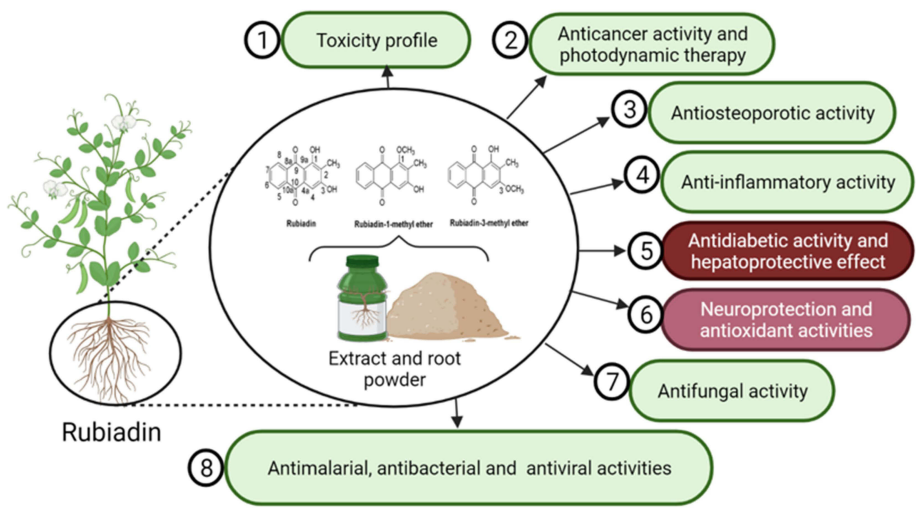

Antidiabetic activity and hepatoprotective effect

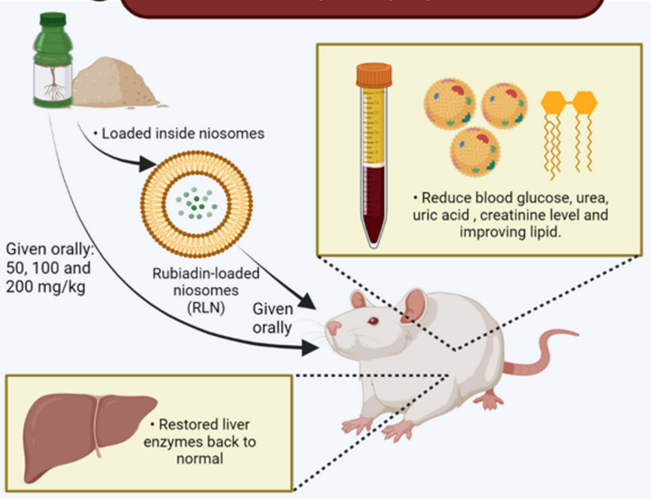

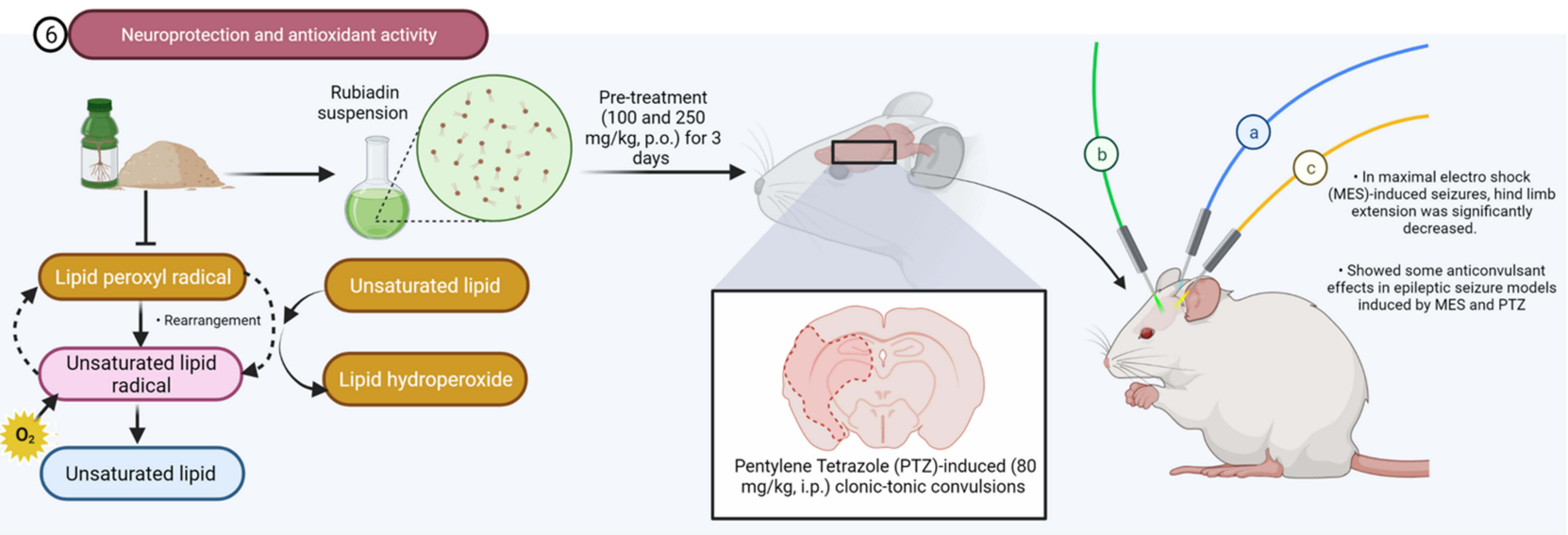

Figure 8 Rubiadin's efficacy as an anti-diabetic, hepatoprotective, neuroprotective, and antioxidant. Rubiadin significantly decreased blood glucose and other serum biomarkers associated with the kidney and liver when taken orally, allowing them to return to normal levels. Rubiadin has also been identified as a potential neuroprotective and antioxidant compound, as it inhibits lipid peroxidation in dose-dependent manner in mice suffering from maximal electroshock (MES)-induced seizures.

Note: Created with BioRender.com.

from the studies mentioned above, no in vitro or in vivo antioxidant investigations on Rubiadin have been reported making relating the findings reported in a few models to antioxidant potential a challenge. Further research using a variety of approaches, including animal models with established mechanisms of action, should be conducted in the future to confirm Rubiadin's antioxidant potential.

\section{Antifungal Activity}

AQs and their derived compounds are well documented for their antifungal properties. ${ }^{62,63}$ Bacillus velezensis is a plantgrowth-promoting rhizobacterium with enormous potential for agricultural development. Bacillus velezensis Lle-9 which is isolated from Lilium leucanthum bulbs has shown antifungal activities against plant pathogens such as Botryosphaeria dothidea, Fusarium oxysporum, Botrytis cinerea and Fusarium fujikuroi. The presence of Rubiadin and other antimicrobial compounds in the bacterial culture can assist in isolating Bacillus velezensis Lle-9's antifungal activity. ${ }^{64}$
Marioni et a ${ }^{65}$ who investigated the antifungal effects of Rubiadin and RBME on Candida tropicalis confirmed that both compounds reduced biofilm formation and had an antifungal effect as mediated by oxidative and nitrosative stress under irradiation, with a significant increase in endogenous ROS and superoxide dismutase (SOD) activity. Rubiadin, in particular, altered the pro-oxidant-antioxidant balance. The most prominent effect of irradiation was oxidative stress, which altered the pro-oxidant-antioxidant balance and may contribute to an irreversible cell injury in the biofilm. Rubiadin is also an excellent synergistic combination with Amphotericin $\mathrm{B}$ indicating that the photosensitizing Rubiadin is a promising therapy option for Candida infections. ${ }^{65} \mathrm{~A}$ follow-up study suggested that the $\mathrm{O} 2$ • $^{-}$ formed by an electron transfer quenches the Rubiadin and RBME excited states and is the main photosensitizing mechanism involved in the photo-induced antibiofilm activity. ${ }^{66}$ Additionally, RBME behaves exclusively as a photosensitizer. ${ }^{67}$ 

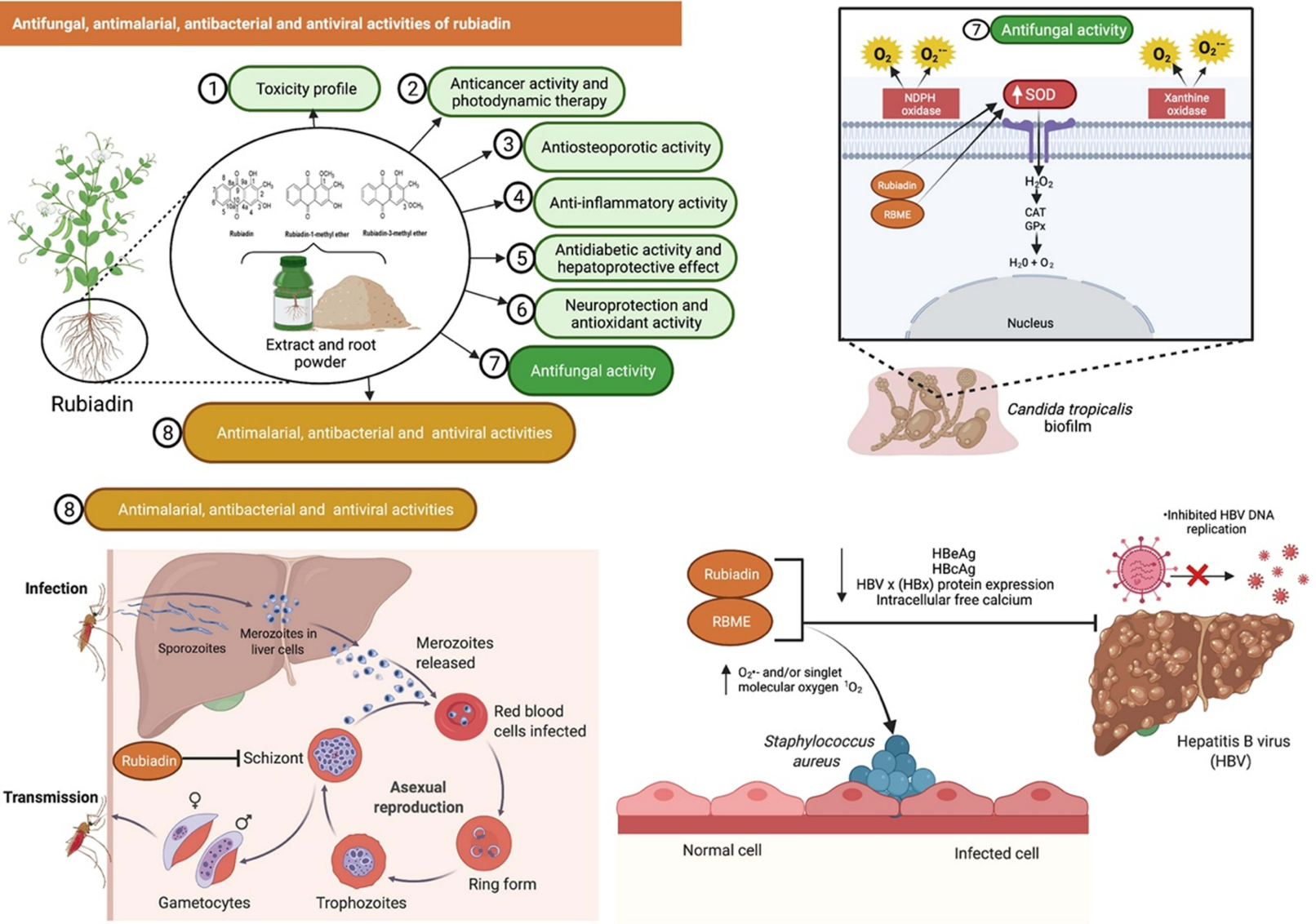

Figure 9 Rubiadin's antifungal activity against Candida tropicalis confirmed that the compound inhibited biofilm formation and exerted antifungal activity with a significant increase in endogenous ROS and SOD activity. Additionally, rubiadin and RBME showed antimalarial and antibacterial properties, as the number of Plasmodium falciparum parasites (schizonts) and Staphylococcus aureus were significantly decreased. Rubiadin was tested against hepatitis B virus (HBV), and the results indicated that it inhibited HBV DNA replication, decreased hepatitis $B$ e antigen $(\mathrm{HBeAg})$ and hepatitis $B$ core antigen $(\mathrm{HBcAg})$ levels, $\mathrm{HBV} \times(\mathrm{HBx})$ protein expression, and intracellular free calcium. Note: Created with BioRender.com.

Abbreviations: ROS, reactive oxygen species; SOD, superoxide dismutase; $\mathrm{H}_{2} \mathrm{O}_{2}$, hydrogen peroxide; CAT, catalase; GPx, glutathione peroxidase; $\mathrm{H}_{2} \mathrm{O}$, water; $\mathrm{O}_{2}$, oxygen; $\mathrm{O}_{2}-$, superoxide anion radical; ' $\mathrm{O}_{2}$, singlet molecular oxygen.

The antifungal activity of Rubiadin has been evaluated against three fungi such as Aspergillus ochraceus, Aspergillus niger and Candida lipolytica where it showed moderate antifungal activity against Aspergillus ochraceus [minimum inhibitory concentration (MIC) of $>80 \mu \mathrm{g} / \mathrm{disc}$ ] (Figure 9). ${ }^{41}$ Overall, the findings suggest that Rubiadin and RBME have antifungal activity against a variety of pathogenic Aspergillus and Candida species. Rubiadin has the potential to be employed as a lead compound in the investigation for the development of a potential antifungal agent.

\section{Antimalarial, Antibacterial and Antiviral Activities}

Rubiadin and RBME have been shown to have antimalarial activities with $\mathrm{IC}_{50}$ values of 13.00 and $1.56 \mu \mathrm{g} / \mathrm{mL}$, respectively. ${ }^{68}$ The number of Plasmodium falciparum parasites (schizonts) decreased significantly in a dosedependent manner with almost a $100 \%$ of inhibition by RBME $(30 \mu \mathrm{g} / \mathrm{mL})^{69}$ indicating that they have the potential to be developed as antiplasmodial agents. Rubiadin and RBME showed antibacterial activity against Staphylococcus aureus with MIC of 32-64 and $>256 \mu \mathrm{g} /$ $\mathrm{mL}$, respectively. The mechanism of action seems to involve an increase in the levels of superoxide anion $\mathrm{O}_{2} \bullet^{-}$and/or singlet molecular oxygen ${ }^{1} \mathrm{O}_{2} \cdot{ }^{70}$ In another study, Rubiadin was investigated against hepatitis B virus (HBV) using HepG2.2.15 cells. Rubiadin inhibited HBV DNA replication and lowered hepatitis $\mathrm{B}$ e antigen ( $\mathrm{HBeAg})$ as well as hepatitis $\mathrm{B}$ core antigen ( $\mathrm{HBcAg}$ ) levels. It also decreased $\mathrm{HBV} \times \mathrm{x}(\mathrm{HBx})$ protein expression and reduced intracellular free calcium suggesting that it is a promising anti-HBV drug candidate (Figure 9). ${ }^{30}$ 


\section{Pharmacokinetics of Rubiadin}

AQs which are absorbed mostly through the intestines and are primarily distributed in tissues and organs that receive good blood supply are transformed into another AQ, leading to potential pharmacological and/or toxicological effects. ${ }^{71}$ The main components of Morinda officinalis are Rubiadin and RBME. To investigate the pharmacokinetics and tissue distribution of these two compounds in rat plasma and tissues, Shi et $\mathrm{al}^{17}$ used an ultra-performance liquid chromatography-tandem mass spectrometry (UPLC-MS/MS). When compared to the findings from Morinda officinalis without wood (MO), the salt-processed Morinda officinalis (SMO) groups had significant increase in the maximum concentration (Cmax) and area under the curve $\left(\mathrm{AUC}_{0-\mathrm{t}}\right)$ indicating that salt steaming can increase Rubiadin's and RBME's bioavailabilities. Rubiadin had a time to maximum concentration $\left(\mathrm{T}_{\max }\right)$ of $1.5 \mathrm{~h}$, which was longer than RBME, although RBME had the highest $\mathrm{C}_{\max }$, particularly in the SMO extract. Additionally, the small intestine had the highest concentrations of both Rubiadin and RBME. Nevertheless, due to the limited study focus on Rubiadin's pharmacokinetic features, a comprehensive assessment of Rubiadin's absorption, distribution, metabolism and excretion profiles remains lacking.

\section{Absorption, Distribution, Metabolism, Excretion, and Toxicity (ADMET) Properties of Rubiadin}

The variable nearest neighbor (vNN)-ADMET webserver was used to predict ADMET properties ${ }^{72}$ of Rubiadin and to build new models based on vNN methodology. The parameters were classified as effects on the liver toxicity profile, metabolism, membrane transporters function, hERG (cardiotoxicity) activity, MMP (mitochondrial toxicity assay), mutagenicity (AMES test), and the maximum recommended therapeutic dose (MRTD). According to the unrestricted prediction model of the program, Rubiadin causes drug-induced liver injury (DILI) but not cytotoxicity, whereas the restricted model has no high confidence prediction. Rubiadin may produce positive findings for the human liver microsomal (HLM) stability assay and according to the unrestricted applicability domain, it may be rapidly metabolized. Rubiadin has the potential to inhibit the CYP 1A2, 2D6, 2C9, and 2C19 enzymes, but not the CYP 3A4 enzymes, as predicted by both models. Rubiadin has been found to have no effect on membrane transporters such as BBB and P-glycoprotein (P-gp).
Rubiadin causes mutations and may cause mitochondrial malfunction, according to the results of the AMES and MMP assays. The MRTD for Rubiadin was found to be $665 \mathrm{mg} /$ day, as predicted by the software.

Apart from the parameters listed above, the toxicity estimation software tool (TEST) was used to estimate Rubiadin toxicity using quantitative structure-activity relationships (QSARs) approaches. ${ }^{73}$ By employing TEST and QSAR techniques, the oral rat $\mathrm{LD}_{50} \mathrm{mg} / \mathrm{kg}$ (predicted value) of Rubiadin was found to be 1307.13, 3502.50 , and $487.82 \mathrm{mg} / \mathrm{kg}$, respectively, to consensus method, hierarchical clustering technique, and nearest neighbor technique. There is a possibility that the mutagenicity assay will be positive, as shown by the software when all three QSAR techniques are used. According to the consensus approach, hierarchical clustering technique, and nearest neighbor technique, the predicted value of the mutagenicity assay was $0.98,0.97$, and 1.00 , respectively.

\section{Molecular Docking of Rubiadin Against the Cancer Target Proteins}

Molecular docking is a computational tool that can predict how a ligand will attach to a protein with a known threedimensional structure. Docking may be used to do computergenerated screening on enormous collections of compounds, rate the outcomes, and offer structural models for in what manner the ligands inhibit the target, which is tremendously beneficial in the search for new inhibitors. There are no literature about molecular docking studies describing the interaction of Rubiadin with molecular targets involved in cancer development. To circumvent this constraint, we employed protein-ligand molecular docking to assess the Rubiadin's binding mechanism and interaction energy with four important enzyme targets, which were identified in this research as being responsible for variety of cancers.

A number of cancer treatments have been evaluated in clinical trials to see if they can inhibit the cMET receptor tyrosine kinase, and resistance mutations in the cMET gene are beginning to be identified in a number of these medications. Molecular investigations are still required to further understand individual cMET modifications at the molecular level, particularly in terms of small molecule identification. ${ }^{74}$ In certain cancers, chromosomal translocation, amplification, or point mutations in the anaplastic lymphoma kinase (ALK) gene cause the tyrosine kinase to be constitutively activated. This gene has been found as a potential target for molecular docking studies, and it will be investigated extensively. ${ }^{75} \mathrm{PI} 5 \mathrm{P} 4 \mathrm{~K}$ s have 
been shown to play a role in the growth of cancer cells as well as the development of other disorders. Due to a lack of effective and selective small drugs on the market, targeting these kinases for therapeutic purposes has gotten little attention. ${ }^{76}$ Hsp90 and Hsp90 have been linked to cancer and neurological disorders, although determining their precise role in these diseases has been difficult due to a lack of specific pharmacological studies. ${ }^{77}$ The protein with the PDB IDs 3AOX, 6OLX, 6OSP, and 6SDC were extracted from the protein data bank to commemorate the above four targets.

Molegro Virtual Docker (MVD) 6.0 was used to conduct the molecular docking study. ${ }^{78}$ The docking procedure includes the following steps. MVD was used to import the molecules, including protein and ligand (Rubiadin). In the protein molecule, potential binding sites and the configuration of the search space were determined. The Docking Wizard was used to run a docking simulation. The Pose Organizer and the ligand energy inspector tool were used to inspect the docking results, and the results were tabulated and the docked view was extracted (Table 3). The MolDock score with the lowest values was discovered to have the highest binding affinity to the target proteins. Rubiadin affinity for cancer targets was found to be $6 \mathrm{SDC}>6 \mathrm{OLX}>3 \mathrm{AOX}>6 \mathrm{OSP}$, according to the report obtained. This result strengthens the anticancer potential of Rubiadin and that could help to enlighten this biologically active compound to the next level of drug discovery and development.

\section{Cosmetic Formulation Containing Rubiadin}

Rubiadin has been used as an active ingredient in a cream formulation conducted by a group of Korean researchers. The researchers reported that it had an excellent antiallergy effect by inhibiting $\beta$-hexosaminidase secretion and the expression of caspase-1. The cream has been patented and relates to a cosmetic composition comprising ceramide, which can relieve atopic symptoms, additionally conferred by its moisturizing effect. ${ }^{79}$

\section{Possible Structural Modifications in Rubiadin}

Currently, it remains unclear whether the bioactivities of Rubiadin can be improved via structural modifications. Some analogues of Rubiadin have been isolated or synthesized using methylation and acylation reactions, which are possible due to their phenolic hydroxyl groups. The sidechain modifications is an impetus for further efforts to increase the therapeutic potential of this class of compounds (Figure 10). For example, Rubiadin analogues 1-3 have been synthesised and their cytotoxic activities against MCF-7 and K-562 cancer cell lines and the structure-activity relationship have been described. ${ }^{80}$ The structure-activity relationship suggested that methoxy and hydroxyl groups are important for the cytotoxicity and selectivity of the substituted AQs. Further RBME 4 and Rubiadin-3-methyl ether 5 were isolated from different medicinal plants and some of their biological activities were investigated (Table 1). Additionally, Rubiadin-1methyl ether-3-O- $\beta$-primeveroside $\mathbf{6}$ has been isolated, characterised and reported from Pentas lanceolata. ${ }^{81}$

The in silico design of more potent Rubiadin derivatives can be used as a way forward for novel drug discovery and development. Nevertheless, in vitro and in vivo studies should be conducted in future to confirm the safety and efficacy of all semi-synthetic derivatives of Rubiadin. Additionally, more studies relating to its structure-activity relationship (SAR) are warranted in the future to obtain several other novel compounds derived from Rubiadin.

\section{Conclusion and Future Perspectives}

In this review, the presence of Rubiadin in medicinal plants and its isolation, synthesis, structural characterization, physicochemical properties, along with its biosynthesis are described in detail. Additionally, the scientific updates on its biological and therapeutic potentials have been provided. Accumulating evidence provided by various preclinical studies has shown that Rubiadin can be a promising anticancer, anti-osteoporotic, hepatoprotective, neuroprotective, anti-inflammatory, antidiabetic, antioxidant, antibacterial, antimalarial, antifungal and antiviral drug candidate for further development. Rubiadin was proven to have the highest binding affinity to the cancer targeted proteins in an in silico study, thus we believe it may be a potential anticancer molecule. The in silico findings indicate that Rubiadin has a high ligand-potentiality for a wide range of macromolecules, leading us to believe that it may interact with a variety of other enzymes or proteins that were not included in this simulation. It is hoped that this review will stimulate further investigations on Rubiadin in relation to its pharmacokinetics, pharmacodynamics, clinical and SAR studies, which can help accelerate the development and utilization of Rubiadin as a promising drug candidate in the near future. 


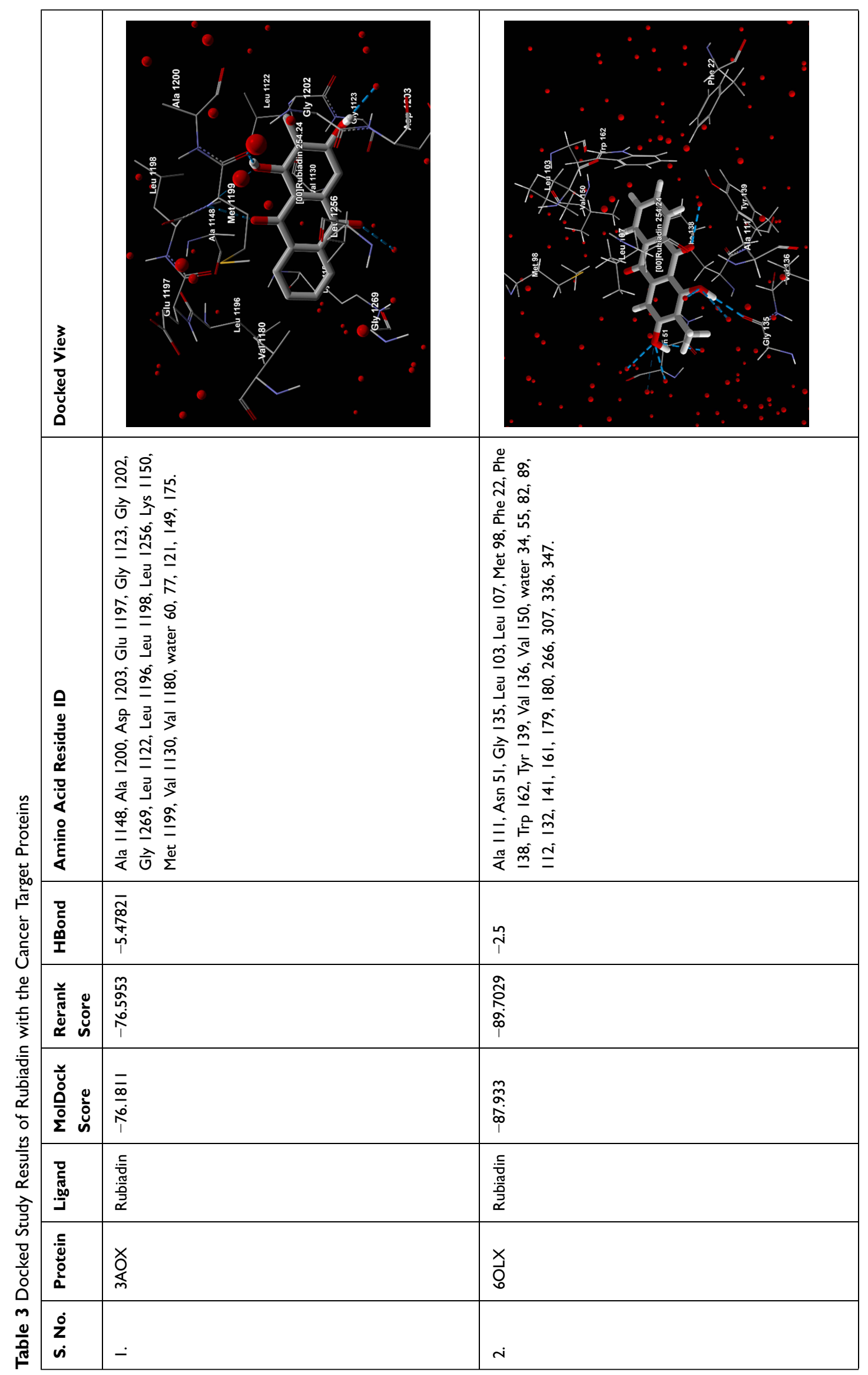




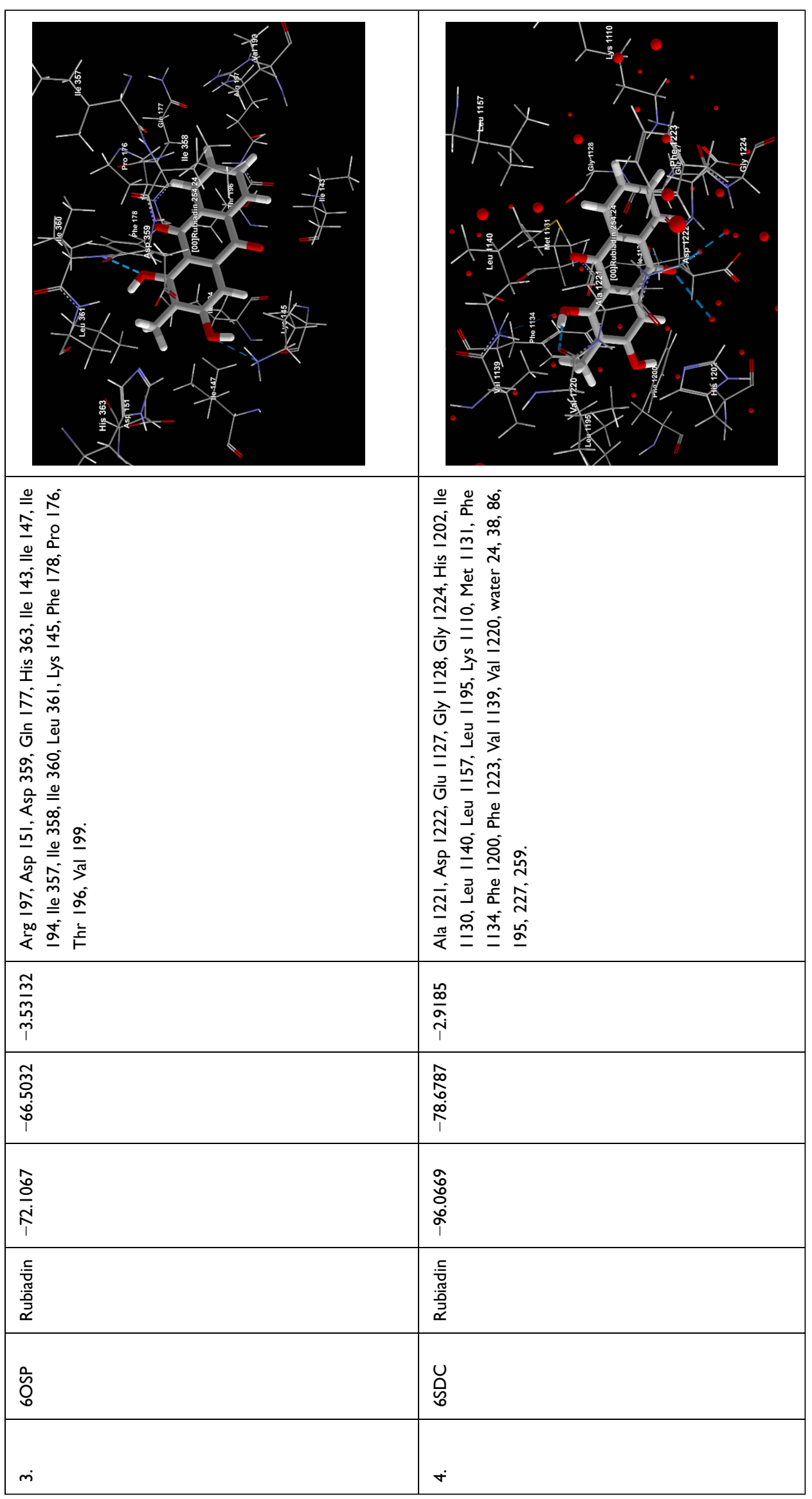


<smiles>[R]c1cc2c(c([R])c1[R])C(=O)c1ccccc1C2=O</smiles>

Rubiadin
1
2
3
R1 OCH3;
R2 CH3; R2 CH3; $\mathrm{R2} \mathrm{CH}_{3}$ R2 CH3;<smiles>COc1c(C)c(O)cc2c1C(=O)c1ccccc1C2=O</smiles>

Figure 10 Possible structural modifications of Rubiadin. Note: Created with ChemDraw Ultra 8.0.

\section{Consent for Publication}

The final version of the manuscript was reviewed by all the authors who consented to its submission.

\section{Acknowledgments}

The authors acknowledge AIMST University, Kedah, Malaysia, and Universiti Kuala Lumpur Royal College of Medicine Perak, Ipoh, Perak, Malaysia, for providing the facilities and services required to complete the study. The figures and graphical abstract in this manuscript were created with BioRender.com and the support of https:// biorender.com under a paid subscription.

\section{Author Contributions}

All the authors made substantial contributions to conception and design, acquisition of data, or analysis and interpretation of data; took part in drafting the article or revising it critically for important intellectual content; agreed to submit to the current journal; gave final approval of the version to be published; and agree to be accountable for all aspects of the work.

\section{Funding}

There is no funding to report.

\section{Disclosure}

The authors have no conflict of interest associated with the publication and report no conflicts of interest for this work. There was also no significant financial support for this work.<smiles>COc1cc2c(c(O)c1C)C(=O)c1ccccc1C2=O</smiles>

$3 \mathrm{OH}$ $\mathrm{OCH} 3$ R3 OAC<smiles>COc1c(OC2OC3(COC4OC(O)C(O)C(O)C4O)COC(O3)C(O)C2O)cc2c(c1C)C(=O)c1ccccc1C2=O</smiles>

\section{References}

1. Duval J, Pecher V, Poujol M, Lesellier E. Research advances for the extraction, analysis and uses of anthraquinones: a review. Ind Crops Prod. 2016;94:812-833. doi:10.1016/j.indcrop.2016.09.056

2. Seigler DS. Benzoquinones, naphthoquinones, and anthraquinones. In: Plant Secondary Metabolism. Springer; 1998.

3. Dave H, Ledwani L. A review on anthraquinones isolated from Cassia species and their applications. Indian $J$ Natl Prod Resources. 2012;3(2012):291-319.

4. Malik EM, Müller CE. Anthraquinones as pharmacological tools and drugs. Med Res Rev. 2016;36(4):705-748. doi:10.1002/ med.21391

5. Huang Q, Lu G, Shen HM, Chung MC, Ong CN. Anti-cancer properties of anthraquinones from rhubarb. Med Res Rev. 2007;27 (5):609-630. doi:10.1002/med.20094

6. Murdock K, Child R, Fabio P, et al. Antitumor agents. 1. 1, 4-Bis [(aminoalkyl) amino]-9, 10-anthracenediones. $J$ Med Chem. 1979;22(9):1024-1030. doi:10.1021/jm00195a002

7. Shrestha JP, Fosso MY, Bearss J, Chang C-WT. Synthesis and anticancer structure activity relationship investigation of cationic anthraquinone analogs. Eur J Med Chem. 2014;77:96-102. doi:10.1016/j.ejmech.2014.02.060

8. Shrestha JP, Subedi YP, Chen L, Chang C-WT. A mode of action study of cationic anthraquinone analogs: a new class of highly potent anticancer agents. MedChemComm. 2015;6(11):20122022. doi:10.1039/C5MD00314H

9. Chien S-C, Wu Y-C, Chen Z-W, Yang W-C. Naturally occurring anthraquinones: chemistry and therapeutic potential in autoimmune diabetes. Evid Based Complement Altern Med. 2015;2015:1-13. doi:10.1155/2015/357357

10. Khan K, Karodi R, Siddiqui A, Thube S, Rub R. Development of anti-acne gel formulation of anthraquinones rich fraction from Rubia cordifolia (Rubiaceae). Int J Appl Res Nat Prod. 2011;4 (4):28-36.

11. Davis RH, Agnew PS, Shapiro E. Antiarthritic activity of anthraquinones found in aloe vera for podiatric medicine. $J$ Am Podiatr Med Assoc. 1986;76(2):1-8.

12. Wuthi-udomlert M, Kupittayanant P, Gritsanapan W. In vitro evaluation of antifungal activity of anthraquinone derivatives of Senna alata. $J$ Health Res. 2010;24(3):117-122. 
13. Fosso MY, Chan KY, Gregory R, Chang C-WT. Library synthesis and antibacterial investigation of cationic anthraquinone analogs. ACS Comb Sci. 2012;14(3):231-235. doi:10.1021/co2002075

14. Winter R, Cornell KA, Johnson LL, Ignatushchenko M, Hinrichs DJ, Riscoe MK. Potentiation of the antimalarial agent rufigallol. Antimicrob Agents Chemother. 1996;40(6):1408-1411. doi:10.1128/ AAC.40.6.1408

15. Tikhomirov AS, Shtil AA, Shchekotikhin AE. Advances in the discovery of anthraquinone-based anticancer agents. Recent Pat Anticancer Drug Discov. 2018;13(2):159-183. doi:10.2174/ 1574892813666171206123114

16. Rao GMM, Rao CV, Pushpangadan P, Shirwaikar A. Hepatoprotective effects of rubiadin, a major constituent of Rubia cordifolia Linn. J Ethnopharmacol. 2006;103(3):484-490. doi:10.1016/j.jep.2005.08.073

17. Shi J, Ren X, Wang J, Wei X, Liu B, Jia T. Effects of the saltprocessing method on the pharmacokinetics and tissue distribution of orally administered Morinda officinalis how. Extract $J$ Analyt Methods Chem. 2020;2020:1-11.

18. Patel V, Patel R. Simultaneous analysis and quantification of markers of manjisthadi churna using high performance thin layer chromatography. Indian J Pharm Sci. 2013;75(1):106. doi:10.4103/0250-474X.113541

19. Zhang J, Zhang Z, Bao J, et al. Jia-Jian-Di-Huang-Yin-Zi decoction reduces apoptosis induced by both mitochondrial and endoplasmic reticulum caspase12 pathways in the mouse model of Parkinson's disease. $J$ Ethnopharmacol. 2017;203:69-79. doi:10.1016/j.jep.2016.12.053

20. Qin L, Han T, Zhang Q, et al. Antiosteoporotic chemical constituents from Er-Xian Decoction, a traditional Chinese herbal formula. J Ethnopharmacol. 2008;118(2):271-279. doi:10.1016/j. jep.2008.04.009

21. Bhatt P, Kushwah A. Rubia cordifolia overview: a new approach to treat cardiac disorders. Int J Drug Dev Res. 2013;5(2):47-54.

22. Ojha JK, Dwivedi KN, Chaurasiya AK. Effect of Rubia cordifolia on non healing diabetic foot ulcer. Nat Sem Trad Med Plants Skin Care. 1994:17.

23. Gogate VU. Ramkrishnan S (editor). Ayurvedic Pharmacology and Therapeutic Uses of Medicinal Plants (Dravya-gunavignyan). Mumbai: Swami Prakashananda Ayurveda Research Centre; 2000.

24. Lodia S, Kansala L. Antioxidant activity of Rubia cordifolia against lead toxicity. Int J Pharma Sci Res. 2012;3(7):2224.

25. Tripathi YB, Singh AV. Role of Rubia cordifolia Linn. in radiation protection. Future Med Chem. 2007;12(7):627-644.

26. Karodi R, Jadhav M, Rub R, Bafna A. Evaluation of the wound healing activity of a crude extract of Rubia cordifolia L. (Indian madder) in mice. Int J Appl Res Nat Prod. 2009;2(2):12-18.

27. Prajapati SN, Parmar KA. Anti-viral and in-vitro free radical scavenging activity of leaves of Rubia cordifolia. Int $J$ Phytomed. 2011;3(1):98.

28. Tripathi Y, Sharma M, Manickam M. Rubiadin, a new antioxidant from Rubia cordifolia. Indian J Biochem Biophys. 1997;34 (3):302-306.

29. Takano T, Kondo T, Nakatsubo F. Facile synthesis of rubiadin by microwave heating. J Wood Sci. 2006;52(1):90-92. doi:10.1007/ s10086-005-0727-6

30. Peng Z, Fang G, Peng F, et al. Effects of Rubiadin isolated from Prismatomeris connata on anti-hepatitis B virus activity in vitro. Phytother Res. 2017;31(12):1962-1970. doi:10.1002/ptr.5945

31. National Center for Biotechnology Information. PubChem compound summary for CID 124062, Rubiadin. Avaiable from: https://pubchem. ncbi.nlm.nih.gov/compound/Rubiadin. Accessed October 20, 2021.

32. Lipinski CA, Lombardo F, Dominy BW, Feeney PJ. Experimental and computational approaches to estimate solubility and permeability in drug discovery and development settings. Adv Drug Deliv Rev. 1997;23(1-3):3-25. doi:10.1016/S0169-409X(96)00423-1
33. Zhang M-Q, Wilkinson B. Drug discovery beyond the 'rule-offive'. Curr Opin Biotechnol. 2007;18(6):478-488. doi:10.1016/j. copbio.2007.10.005

34. Shukla V, Asthana S, Gupta P, Dwivedi PD, Tripathi A, Das M. Toxicity of naturally occurring anthraquinones. In: Advances in Molecular Toxicology. Vol. 11. Elsevier; 2017.

35. Verma A, Mahalwal V, Kumar B. Antiepileptic activity of rubiadin isolated from the roots of Rubia cordifolia in mice. Int $J$ Pharma Sci Res. 2019;10:3022-3028.

36. Tian W, Wang C, Li D, Hou H. Novel anthraquinone compounds as anticancer agents and their potential mechanism. Future Med Chem. 2020;12(7):627-644.

37. Cogno IS, Gilardi P, Comini L, Núñez-Montoya SC, Cabrera JL, Rivarola VA. Natural photosensitizers in photodynamic therapy: in vitro activity against monolayers and spheroids of human colorectal adenocarcinoma SW480 cells. Photodiagnosis Photodyn Ther. 2020;31:101852. doi:10.1016/j.pdpdt.2020.101852

38. Comini L, Fernandez I, Vittar NR, Montoya SN, Cabrera J, Rivarola V. Photodynamic activity of anthraquinones isolated from Heterophyllaea pustulata Hook f. (Rubiaceae) on MCF-7c3 breast cancer cells. Phytomedicine. 2011;18(12):1093-1095. doi:10.1016/j.phymed.2011.05.008

39. Vittar NBR, Comini L, Fernadez IM, et al. Photochemotherapy using natural anthraquinones: Rubiadin and Soranjidiol sensitize human cancer cell to die by apoptosis. Photodiagnosis Photodyn Ther. 2014;11(2):182-192. doi:10.1016/j.pdpdt.2014.02.002

40. Chiou C-T, Hsu R-Y, Lin L-C. Isolation and cytotoxic effect of anthraquinones from Morinda umbellata. Planta Med. 2014;80 (13):1113-1117. doi:10.1055/s-0034-1382956

41. Ali A, Ismail N, Mackeen M, et al. Antiviral, cyototoxic and antimicrobial activities of anthraquinones isolated from the roots of Morinda elliptica. Pharm Biol. 2000;38(4):298-301. doi:10.1076/1388-0209(200009)38:4;1-A;FT298

42. Kanokmedhakul K, Kanokmedhakul S, Phatchana R. Biological activity of anthraquinones and triterpenoids from prismatomeris fragrans. J Ethnopharmacol. 2005;100(3):284-288. doi:10.1016/j. jep.2005.03.018

43. Inoue K, Yoshida M, Takahashi M, et al. Possible contribution of rubiadin, a metabolite of madder color, to renal carcinogenesis in rats. Food Chem Toxicol. 2009;47(4):752-759. doi:10.1016/j. fct.2009.01.003

44. Inoue $\mathrm{K}$, Yoshida M, Takahashi M, et al. Carcinogenic potential of alizarin and rubiadin, components of madder color, in a rat medium-term multi-organ bioassay. Cancer Sci. 2009;100 (12):2261-2267. doi:10.1111/j.1349-7006.2009.01342.x

45. Blömeke B, Poginsky B, Schmutte C, Marquardt H, Westendorf J. Formation of genotoxic metabolites from anthraquinone glycosides, present in Rubia tinctorum L. Mutat Res/Fundament Mol Mechan Mutagen. 1992;265(2):263-272. doi:10.1016/0027-5107 (92)90055-7

46. Siewert B, Stuppner H. The photoactivity of natural products-an overlooked potential of phytomedicines? Phytomedicine. 2019;60:152985. doi:10.1016/j.phymed.2019.152985

47. Montoya SCN, Comini LR, Vittar BR, Fernández IM, Rivarola VA, Cabrera JL. Phototoxic effects of Heterophyllaea pustulata (Rubiaceae). Toxicon. 2008;51(8):1409-1415. doi:10.1016/j. toxicon.2008.03.011

48. Micheloud JF, Colque-Caro LA, Comini LR, et al. Spontaneous photosensitization by Heterophyllaea pustulata Hook. f. (Rubiaceae), in sheep from Northwestern Argentina. Trop Anim Health Prod. 2017;49(7):1553-1556. doi:10.1007/s11250-0171354-0

49. Micheloud JF, Aguirre LS, Marioni J, et al. Experimental poisoning by Heterophyllaea pustulata Hook. f. (Rubiaceae) in goats. Clinical, biochemical and toxicological aspects. Toxicon. 2019;165:56-61. doi:10.1016/j.toxicon.2019.04.015 
50. Sambrook P, Cooper C. Osteoporosis. Lancet. 2006;367 (9527):2010-2018. doi:10.1016/S0140-6736(06)68891-0

51. He Y-Q, Zhang Q, Shen Y, et al. Rubiadin-1-methyl ether from Morinda officinalis How. Inhibits osteoclastogenesis through blocking RANKL-induced NF- $\mathrm{B}$ pathway. Biochem Biophys Res Commun. 2018;506(4):927-931. doi:10.1016/j.bbrc.2018.1 0.100

52. Bao L, Qin L, Liu L, et al. Anthraquinone compounds from Morinda officinalis inhibit osteoclastic bone resorption in vitro. Chem Biol Interact. 2011;194(2-3):97-105. doi:10.1016/j. cbi.2011.08.013

53. Wu Y-B, Zheng C-J, Qin L-P, et al. Antiosteoporotic activity of anthraquinones from Morinda officinalis on osteoblasts and osteoclasts. Molecules. 2009;14(1):573-583. doi:10.3390/molecul es14010573

54. Xia T, Dong X, Lin L, et al. Metabolomics profiling provides valuable insights into the underlying mechanisms of Morinda officinalis on protecting glucocorticoid-induced osteoporosis. $J$ Pharm Biomed Anal. 2019;166:336-346. doi:10.1016/j.jpba.20 19.01.019

55. Libby P. Inflammatory mechanisms: the molecular basis of inflammation and disease. Nutr Rev. 2007;65(suppl_3):S140S146. doi:10.1301/nr.2007.dec.S140-S146

56. Mohr ETB, Dos Santos Nascimento MVP, da Rosa JS, et al. Evidence that the anti-inflammatory effect of Rubiadin-1-methyl ether has an immunomodulatory context. Mediators Inflamm. 2019;2019:1-12. doi:10.1155/2019/6474168

57. Mujeeb M, Ahad A, Aqil M, et al. Ameliorative effect of rubiadin-loaded nanocarriers in STZ-NA-induced diabetic nephropathy in rats: formulation optimization, molecular docking, and in vivo biological evaluation. Drug Deliv Transl Res. 2021;1-14. doi:10.1007/s13346-021-00971-0

58. Yen G-C, Duh P-D, Chuang D-Y. Antioxidant activity of anthraquinones and anthrone. Food Chem. 2000;70(4):437-441. doi:10.1016/S0308-8146(00)00108-4

59. Malterud KE, Farbrot TL, Huse AE, Sund RB. Antioxidant and radical scavenging effects of anthraquinones and anthrones. Pharmacology. 1993;47(Suppl. 1):77-85. doi:10.1159/000139846

60. Baghiani A, Charef N, Djarmouni M, Saadeh A, Arrar L, Mubarak S. Free radical scanvenging and antioxidant effects of some anthraquinone derivatives. Med Chem (Los Angeles). 2011;7(6):639-644. doi:10.2174/157340611797928424

61. Tripathi Y, Sharma M. Comparison of the antioxidant action of the alcoholic extract of Rubia cordifolia with rubiadin. Indian $J$ Biochem Biophys. 1998;35(5):313-316.

62. Mishra BB, Kishore N, Tiwari VK, Singh DD, Tripathi V. A novel antifungal anthraquinone from seeds of Aegle marmelos Correa (family Rutaceae). Fitoterapia. 2010;81(2):104-107. doi:10.1016/j.fitote.2009.08.009

63. Mohamadzadeh M, Zarei M, Vessal M. Synthesis, in vitro biological evaluation and in silico molecular docking studies of novel $\beta$-lactam-anthraquinone hybrids. Bioorg Chem. 2020;95:103515. doi:10.1016/j.bioorg.2019.103515

64. Khan MS, Gao J, Chen X, et al. The endophytic bacteria Bacillus velezensis Lle-9, isolated from Lilium leucanthum, harbors antifungal activity and plant growth-promoting effects. $J$ Microbiol Biotechnol. 2020;30(5):668-680. doi:10.4014/jmb.1910.10021

65. Marioni J, Da Silva MA, Cabrera JL, Montoya SCN, Paraje MG. The anthraquinones rubiadin and its 1-methyl ether isolated from Heterophyllaea pustulata reduces Candida tropicalis biofilms formation. Phytomedicine. 2016;23(12):1321-1328. doi:10.1016/j. phymed.2016.07.008

66. Marioni J, Bresoli-Obach R, Agut M, et al. On the mechanism of Candida tropicalis biofilm reduction by the combined action of naturally-occurring anthraquinones and blue light. PLoS One. 2017;12(7):e0181517. doi:10.1371/journal.pone.0181517
67. Montoya SCN, Comini LR, Sarmiento M, et al. Natural anthraquinones probed as type I and type II photosensitizers: singlet oxygen and superoxide anion production. J Photochem Photobiol B. 2005;78(1):77-83. doi:10.1016/j.jphotobiol.2004.09.009

68. Likhitwitayawuid K, Dej-adisai S, Jongbunprasert V, Krungkrai J. Antimalarials from Stephania venosa, Prismatomeris sessiliflora, Diospyros Montana and Murraya siamensis1. Planta Med. 1999;65(08):754-756. doi:10.1055/s-2006-960858

69. Koumaglo K, Gbeassor M, Nikabu O, De Souza C, Werner W. Effects of three compounds extracted from Morinda lucida on Plasmodium falciparum. Planta Med. 1992;58(06):533-534. doi:10.1055/s-2006-961543

70. Comini L, Montoya SN, Páez P, Argüello GA, Albesa I, Cabrera J. Antibacterial activity of anthraquinone derivatives from Heterophyllaea pustulata (Rubiaceae). J Photochem Photobiol B. 2011;102(2):108-114. doi:10.1016/j.jphotobiol.2010.09.009

71. Wang D, Wang X-H, Yu X, et al. Pharmacokinetics of anthraquinones from medicinal plants. Front Pharmacol. 2021;12:306.

72. Schyman P, Liu R, Desai V, Wallqvist A. vNN web server for ADMET predictions. Front Pharmacol. 2017;8:889. doi:10.3389/ fphar.2017.00889

73. EPA. User's guide for T.E.S.T. (version 5.1) (toxicity estimation software tool): a program to estimate toxicity from molecular structure. Avaiable from: https://www.epa.gov/chemical-research/toxi city-estimation-software-tool-test. Accessed October 20, 2021.

74. Collie GW, Koh CM, O'Neill DJ, et al. Structural and molecular insight into resistance mechanisms of first generation cMET inhibitors. ACS Med Chem Lett. 2019;10(9):1322-1327. doi:10.1021/acsmedchemlett.9b00276

75. Sakamoto H, Tsukaguchi T, Hiroshima S, et al. CH5424802, a selective ALK inhibitor capable of blocking the resistant gatekeeper mutant. Cancer Cell. 2011;19(5):679-690. doi:10.1016/j. ccr.2011.04.004

76. Sivakumaren SC, Shim H, Zhang T, et al. Targeting the PI5P4K lipid kinase family in cancer using covalent inhibitors. Cell Chem Biol. 2020;27(5):525-537. doi:10.1016/j.chembiol.2020.02.003

77. Huck JD, Que NL, Sharma S, Taldone T, Chiosis G, Gewirth DT. Structures of Hsp90 $\alpha$ and Hsp90 $\beta$ bound to a purine-scaffold inhibitor reveal an exploitable residue for drug selectivity. Proteins Struct Func Bioinform. 2019;87(10):869-877. doi: $10.1002 /$ prot. 25750

78. Thomsen R, Christensen MH. MolDock: a new technique for high-accuracy molecular docking. J Med Chem. 2006;49 (11):3315-3321. doi:10.1021/jm051197e

79. Cosmetic components comprised of the rubiadin having antiallergy activity. Patent number KR101337564B1. Korea Kolmar Co., Ltd.; 2010. Available from: https://patents.google.com/ patent/KR101337564B1/en. Accessed October 28, 2021.

80. Akhtar MN, Zareen S, Yeap SK, et al. Total synthesis, cytotoxic effects of damnacanthal, nordamnacanthal and related anthraquinone analogues. Molecules. 2013;18(8):10042-10055. doi:10.339 0/molecules 180810042

81. Kumar P, Sharma AK, Shukla P. Physiochemical screening of marker anthraquinones and derivatives from the Pentas lanceolata (Forss. k.) deflers leaves. Eur J Pharm Med Res. 2017;4(5):439-446.

82. Dosseh C, Tessier A, Delaveau P. Nouvelles Quinones des Racines de Rubia cordifolia L., III. Planta Med. 1981;43 (12):360-366. doi:10.1055/s-2007-971524

83. Shen C-H, Liu C-T, Song X-J, et al. Evaluation of analgesic and anti-inflammatory activities of Rubia cordifolia L. by spectrumeffect relationships. $J$ Chromatogr B. 2018;1090:73-80. doi:10.1016/j.jchromb.2018.05.021

84. Liu Q, Kim SB, Ahn JH, Hwang BY, Kim SY, Lee MK. Anthraquinones from Morinda officinalis roots enhance adipocyte differentiation in 3T3-L1 cells. Nat Prod Res. 2012;26(18):17501754. doi: $10.1080 / 14786419.2011 .608676$ 
85. Zhang J-H, Xin H-L, Xu Y-M, et al. Morinda officinalis How.-a comprehensive review of traditional uses, phytochemistry and pharmacology. J Ethnopharmacol. 2018;213:230-255. doi:10.1016/j. jep.2017.10.028

86. Zhao X, Wei J, Yang M. Simultaneous analysis of iridoid glycosides and anthraquinones in Morinda officinalis using UPLCQqQ-MS/MS and UPLC-Q/TOF-MSE. Molecules. 2018;23 (5):1070. doi:10.3390/molecules23051070

87. Mugas ML, Marioni J, Martinez F, et al. Inactivation of herpes simplex virus by photosensitizing anthraquinones isolated from heterophyllaea pustulata. Planta Med. 2021;80:716-723.

88. Schunck HE. III. On rubian and its products of decomposition. Philos Transact Royal Soc London. 1853;(143):67-107. doi:10.1098/rstl.1853.0003

89. Kawasaki Y, Goda Y, Yoshihira K. The mutagenic constituents of Rubia tinctorum. Chem Pharm Bull (Tokyo). 1992;40(6):15041509. doi:10.1248/cpb.40.1504

90. Cuoco G, Mathe C, Archier P, Chemat F, Vieillescazes C. A multivariate study of the performance of an ultrasound-assisted madder dyes extraction and characterization by liquid chromatography-photodiode array detection. Ultrason Sonochem. 2009;16 (1):75-82. doi:10.1016/j.ultsonch.2008.05.014

91. Cooksey C. Quirks of dye nomenclature. 14. Madder: queen of red dyes. Biotech Histochem. 2020;95(6):474-482. doi:10.1080/ 10520295.2020.1714079

92. Tuntiwachwuttikul P, Butsuri Y, Sukkoet P, Prawat U, Taylor WC. Anthraquinones from the roots of Prismatomeris malayana. Nat Prod Res. 2008;22(11):962-968. doi:10.1080/14786410701650261

93. Rahman MM. Evaluation of Hymenodictyon excelsum phytochemical's therapeutic value against prostate cancer by molecular Docking study. Jundishapur j Nat Pharma Prod. 2015;10(1). doi:10.17795/jjnpp-18216

94. Ahmad R, Shaari K, Lajis NH, Hamzah AS, Ismail NH, Kitajima M. Anthraquinones from Hedyotis capitellata. Phytochemistry. 2005;66(10):1141-1147. doi:10.1016/j.phytochem.2005.02.023

95. Usai M, Marchetti M. Anthraquinone distribution in the hypogeal apparatus of Rubia peregrina L. growing wild in Sardinia. Nat Prod Res. 2010;24(7):626-632. doi:10.1080/14786410902884842

96. Bussmann RW, Hennig L, Giannis A, Ortwein J, Kutchan TM, Feng X. Anthraquinone content in Noni (Morinda citrifolia L.). Evid Based Complement Altern Med. 2013;2013:1-5. doi: $10.1155 / 2013 / 208378$

97. Rajan R, Venkataraman R, Baby S. A new lupane-type triterpenoid fatty acid ester and other isolates from Ophiorrhiza shendurunii. Nat Prod Res. 2016;30(19):2197-2203. doi:10.1080/ 14786419.2016.1160232

98. Osman CP, Ismail NH, Ahmad R, Ahmat N, Awang K, Jaafar FM. Anthraquinones with antiplasmodial activity from the roots of Rennellia elliptica Korth. (Rubiaceae). Molecules. 2010;15 (10):7218-7226. doi:10.3390/molecules 15107218

99. Yuan S, Zhao Y. Chemical constituents of Knoxia valerianoides. Acta Pharmaceutica Sinica. 2006;41(8):735-737.
100. Yoo NH, Jang DS, Lee YM, et al. Anthraquinones from the roots of Knoxia valerianoides inhibit the formation of advanced glycation end products and rat lens aldose reductase in vitro. Arch Pharm Res. 2010;33(2):209-214. doi:10.1007/s12272-010-0204-7

101. Zhao F, Wang S-J, Lin S, et al. Anthraquinones from the roots of Knoxia valerianoides. J Asian Nat Prod Res. 2011;13(11):10231029. doi:10.1080/10286020.2011.606813

102. Lan M, Luo C, Tan C, Chen L, Wei S, Zhu D. Study on chemical constituents of the ethyl acetate extract from Blumea aromatica. $J$ Chin Med Mater. 2012;35(2):229-231.

103. Jiang J-S, Feng Z-M, Zhang P-C. Chemical constituents from root of Prismatomeris tetrandra. China J Chin Materia Medica. 2005;30(22):1751-1753.

104. Huang W, Li Y, Jiang J. Chemical constituents from Hedyotis diffusa. China J Chin Materia Medica. 2009;34(6):712-714.

105. Liu G, Chen Z, Yao T, Ding W. Studies on the chemical constituents of Rhynchotechum vestitum Hook. F. et Thoms. Acta Pharmaceutica Sinica. 1990;25(9):699-704.

106. Haque MA, Khan G, Razzaque S, Khatun K, Chakraborty AK, Alam MS. Extraction of rubiadin dye from Swietenia mahagoni and its dyeing characteristics onto silk fabric using metallic mordants. Indian J Fibre Text Res. 2013;38:280-284.

107. Li S, Ouyang Q, Tan X, Shi S, Yao Z. Chemical constituents of Morinda officinalis how. China J Chin Materia Medica. 1991;16 (11):675-676, 703 .

108. Chokchaisiri S, Siriwattanasathien Y, Thongbamrer C, Suksamrarn A, Rukachaisirikul T. Morindaquinone, a new bianthraquinone from Morinda coreia roots. Nat Prod Res. 2019;1-7. doi:10.1080/14786419.2019.1705820

109. Zou X, Liang J, Ding L-S, Peng S-L. Studies on chemical constituents of Paederia scandense. China J Chin Materia Medica. 2006;31(17):1436-1441.

110. Li Y, Qi S, Chen X, Hu Z. Separation and determination of the anthraquinones in Xanthophytum attopvensis pierre by nonaqueous capillary electrophoresis. Talanta. 2005;65(1):15-20.

111. Tosa H, Iinuma M, Asai F, et al. Anthraquinones from Neonauclea calycina and their inhibitory activity against DNA topoisomerase II. Biol Pharm Bull. 1998;21(6):641-642. doi:10.1248/bpb.21.641

112. Khanh PN, Huong TT, Spiga O, et al. In silico screening of anthraquinones from Prismatomeris memecyloides as novel phosphodiesterase type-5 inhibitors (PDE-5Is). Revista Internacional De Andrologia. 2018;16(4):147-158. doi:10.1016/j.androl.2017.07.001

113. Chen -R-R, Liu J, Chen Z, Cai W-J, Li X-F, Lu C-L. Anthraquinones extract from morinda angustifolia roxb. Root alleviates hepatic injury induced by carbon tetrachloride through inhibition of hepatic oxidative stress. Evid Based Complement Altern Med. 2020;2020. doi:10.1155/2020/9861571

114. Lv Z, Zhang Q, Chen R, Yu D. Alkaloids and anthraquinones from branches and leaves of Uvaria kurzii. China J Chin Materia Medica. 2011;36(9):1190-1192.

\section{Publish your work in this journal}

Drug Design, Development and Therapy is an international, peerreviewed open-access journal that spans the spectrum of drug design and development through to clinical applications. Clinical outcomes, patient safety, and programs for the development and effective, safe, and sustained use of medicines are a feature of the journal, which has also been accepted for indexing on PubMed Central. The manuscript management system is completely online and includes a very quick and fair peer-review system, which is all easy to use. Visit http://www. dovepress.com/testimonials.php to read real quotes from published authors. 